\title{
Influence d'un déficit ou d'un déséquilibre alimentaire en acides aminés pendant une phase initiale de la croissance sur les performances du porc en finition
}

\author{
Y Henry \\ avec la collaboration de G Conseil, M Lemarié, A Amet, Y Bénard et JC Rissel \\ pour l'expérimentation sur animaux, L Jaffrennou, M Alix, H Renoux et $P$ Surel \\ pour les observations à l'abattage, Nadine Mézière pour l'analyse des régimes \\ et $Y$ Colléaux pour les dosages des acides aminés
}

INRA, station de recherches porcines, 35590 Saint-Gilles, France

(Reçu le 2 novembre 1993; accepté le 5 avril 1994)

\begin{abstract}
Résumé - Une série de 5 expériences a été réalisée sur un effectif total de 476 porcs Large White (femelles et mâles castrés), afin d'étudier l'influence d'un déficit en un acide aminé particulier (lysine, thréonine ou tryptophane) et d'un déséquilibre entre acides aminés (excès de thréonine par rapport à la lysine) pendant une phase initiale de la croissance (18-20 à 40-50 kg de poids vif) sur les performances au poids d'abattage de $100 \mathrm{~kg}$, lorsque les animaux reçoivent un même régime alimentaire de finition suivant un même plan de rationnement. Les résultats montrent que les porcs ont tendance à réagir à un apport sub-optimal de lysine ou de thréonine pendant la période initiale de croissance en augmentant leur consommation d'aliment par unité de poids métabolique. II s'ensuit que la dépression de croissance est associée à un accroissement de l'adiposité, qui est maintenu à l'abattage après que les animaux ont été soumis aux mêmes conditions d'alimentation en période de finition. Au contraire, dans le cas du tryptophane, une réduction de l'apport en dessous du besoin pour la croissance provoque une dépression sévère du niveau d'ingestion alimentaire, qui retentit défavorablement à la fois sur la croissance pondérale et sur le dépôt de gras. Cette autolimitation de la consommation d'aliment conduit à l'abattage à des carcasses plus maigres, après une alimentation normale en finition. En ce qui concerne l'équilibre entre la lysine et la thréonine, un excès de thréonine en présence d'un déficit en lysine induit un effet dépressif sur l'ingestion alimentaire et la vitesse de croissance, comme dans le cas d'une déficience en tryptophane. De la même façon, l'autolimitation initiale de la consommation d'aliment, suivie d'une alimentation normale en finition, produit à l'abattage des carcasses à plus faible état d'engraissement. Dans l'ensemble, les performances en finition ne sont pas ou sont peu affectées par une déficience ou un déséquilibre du régime en acides aminés au cours de la phase de crois-
\end{abstract}


sance antérieure (aux alentours de 20-50 kg), ce qui semble confirmer ainsi l'absence de croissance compensatrice. La longueur de la carcasse à $100 \mathrm{~kg}$ semble augmenter lorsque le ralentissement antérieur de la croissance est associé à une adiposité accrue, comme c'est le cas pour une déficience en lysine. En revanche, elle n'est pas modifiée ou semble diminuer à la suite d'une déficience en tryptophane ou d'un excès de thréonine relativement à la lysine, c'est-à-dire lorsque les dépôts de tissus maigres et de gras sont affectés simultanément. En définitive, les effets d'un déficit ou d'un déséquilibre en acides aminés pendant une phase initiale de la croissance sur les performances ultérieures à l'abattage sont étroitement liés aux variations d'ingestion alimentaire selon la nature du déficit ou du déséquilibre, suivant que les dépôts de tissus maigres et de gras sont distinctement ou simultanément affectés.

porc / croissance / déficit en acide aminé / croissance compensatrice / composition corporelle

Summary - Effect of a dietary amino-acid deficiency or imbalance during the initial period of growth in pigs on subsequent performance at slaughter. A series of 5 experiments was conducted with a total number of 476 Large White pigs (females and castrated males) to study the influence of a deficiency in a particular amino acid (lysine, threonine or tryptophan) and an imbalance between amino acids (excess threonine relative to lysine) during the initial period of growth (18-20 to $40-50 \mathrm{~kg}$ live weight) on final performance at $100 \mathrm{~kg}$ slaughter, when the pigs are fed the same finisher diet at the same feeding level. The results show that the pigs tended to eat more feed per $\mathrm{kg}$ metabolic body weight (BW0.75) when fed a suboptimal level of lysine or threonine. It followed that growth depression was associated with increased adiposity, which was maintained at slaughter after the animals were fed the same diet at the same feeding level during the finishing period of growth. Conversely, in the case of tryptophan, a reduced supply below the level for optimum growth severely depressed voluntary feed intake, with a resulting decrease of both lean and fat deposition. Due to this self-limitation of feed intake, the carcasses were leaner at $100 \mathrm{~kg}$ slaughter weight, following reequilibrated feeding during finishing. With regard to a dietary imbalance between lysine and threonine, an excess of threonine supply in the presence of a limiting supply of lysine exerted a depressive effect on feed intake and growth performance, as in the case of tryptophan deficiency. In the same way, this initial selflimitation of feed consumption, followed by normal feeding during finishing, was associated with lowered fat content in the carcass at $100 \mathrm{~kg}$ slaughter weight. On the whole, growth performance during finishing was little or not affected by amino-acid deficiency or imbalance during the former growth period (around 20-50 kg), and this seems to invalidate the phenomenon of compensatory growth. From the observations at slaughter, it seemed that carcass length increased when the former slowing of growth was connected with increased adiposity, as was the case with lysine deficiency. On the contrary, carcass length was not modified or tended to decrease after tryptophan deficiency or excess threonine relative to lysine, that is when lean and fat deposits were both depressed. To conclude, the effects of dietary amino-acid deficiency or imbalance during the initial phase of growth (between 18-20 and 40-50 kg live weight) on the subsequent growth performance at $100 \mathrm{~kg}$ slaughter weight are closely related to changes in feed intake according to the type of deficiency or imbalance, and depending on whether lean and fat deposits are distinctly or simultaneously affected.

pig / growth / amino-acid deficiency / compensatory growth / body composition

\section{INTRODUCTION}

Un problème d'intérêt majeur dans l'alimentation du porc est d'assurer les apports appropriés de nutriments énergétiques et azotés tout au long des stades successifs de la croissance, afin d'optimiser les performances globales de production et les carac- téristiques finales des carcasses à l'abattage, en fonction d'objectifs fixés préalablement. C'est ainsi que l'on s'est longtemps interrogé sur les conséquences d'une restriction alimentaire, et notamment azotée, pendant une phase initiale de la croissance sur les performances ultérieures à l'abattage, après que les animaux ont été soumis 
de nouveau à une alimentation quantitativement et qualitativement équilibrée. Si une restriction azotée pendant le tout jeune âge est connue pour affecter négativement à long terme le potentiel de développement musculaire (Sève, 1984 ; Sève et Ballèvre, 1991), il semble que ce dernier soit préservé à la suite d'une restriction azotée au cours d'une phase moins précoce de la vie de l'animal. C'est ainsi qu'il est parfois fait état d'une croissance compensatrice pendant une période de réalimentation suivant une période de restriction globale de protéines (Campbell et Biden, 1978 ; Hogberg et Zimmerman, 1978 ; Wahlstrom et Libal, 1983 ; Kyriazakis et al, 1991 ; de Greef et al, 1992) ou simplement de lysine (Thaler et al, 1986), les animaux exprimant un gain pondéral et une efficacité alimentaire souvent améliorés, et dans certains cas un dépôt de gras moindre. En tout état de cause, l'importance de ce phénomène de croissance compensatrice semble dépendre tout autant du stade de croissance au moment de la restriction (Wahlstrom et Libal, 1983) que des aptitudes génétiques des animaux (Hogberg et Zimmerman, 1978 ; de Greef et al, 1992).

Pour mieux comprendre l'incidence d'une restriction azotée sur les performances ultérieures de croissance et la composition corporelle finale, en raison du rôle spécifique de certains acides aminés dans les processus métaboliques (Sève et Ballèvre, 1991) ou ceux liés à l'ajustement de l'ingestion alimentaire (Henry et Sève, 1991, 1993), il nous a paru intéressant de considérer les effets propres de ces derniers, selon leur niveau de déficit ou le type de déséquilibre, en prenant notamment en compte leur contribution spécifique dans les variations d'ingestion alimentaire au cours de la phase de restriction.

L'objet du présent travail était précisément d'étudier l'influence d'un déficit en un acide aminé particulier (lysine, thréonine ou tryptophane) et d'un déséquilibre entre acides aminés (excès de thréonine par rap- port à la lysine) pendant une phase initiale de la croissance (18-20 à 40-50 kg de poids vif) sur les performances du porc au poids habituel d'abattage de $100 \mathrm{~kg}$, lorsque les animaux sont soumis à un même régime alimentaire de finition et à un même plan de rationnement.

\section{MATÉRIEL ET MÉTHODES}

Une série de 5 expériences a été réalisée sur un total de 476 porcs Large White, comportant un nombre égal de femelles et de mâles castrés, d'un poids vif moyen initial par expérience compris entre 17,6 et $21,5 \mathrm{~kg}$. Les traitements alimentaires expérimentaux sont appliqués à volonté pendant une première période d'une durée constante $(42 \mathrm{j}$, à l'exception de l'expérience 3) et jusqu'à un poids vif constant avoisinant $50 \mathrm{~kg}$. Au-delà de ce poids, les animaux sont soumis à un régime unique de finition, suivant un même plan de rationnement alimentaire jusqu'au poids final de $100 \mathrm{~kg}$.

\section{Période expérimentale}

Dans chacune des expériences, à l'issue d'une période pré-expérimentale, les porcs sont répartis entre les traitements selon la méthode des blocs complets équilibrés, sur la base du poids et de l'âge. Ils sont élevés en loges individuelles, sur plancher métallique grillagé ( «flat-deck" : expériences 1 et 2) ou sur sol paillé (expériences 3 à 5). Les aliments sont offerts à volonté, sous forme de granulés (4-5 $\mathrm{mm}$ de diamètre), et l'eau est laissée à discrétion dans un abreuvoir automatique. La composition des régimes de base utilisés dans les 5 expériences est détaillée dans le tableau $\mathrm{I}$. Les teneurs en matières azotées totales ( $N \times 6,25$ : MAT) des régimes expérimentaux sont rééquilibrées après supplémentation en acides aminés sous forme libre, à l'aide d'une addition d'azote non indispensable sous forme de glycine. La valeur énergétique des régimes est de 13,4 MJ d'énergie digestible par $\mathrm{kg}$ d'aliment frais en moyenne. À la fin de la période expérimentale (à l'exception de l'expérience 1), on procède à la mesure de l'épaisseur du lard dorsal aux ultra-sons, latéralement à $6 \mathrm{~cm}$ au niveau du cou, du dos et du rein. Les teneurs en acides aminés sont celles qui ont été mesurées après 
Tableau I. Composition des régimes témoins et du régime de finition dans les 5 expériences (\%).

Expérience

\begin{tabular}{|c|c|c|c|c|c|c|}
\hline \multirow{2}{*}{ - } & & & & & & \\
\hline & 1 & 2 & 3 & 4 & 5 & \\
\hline Orge & - & - & - & - & - & 24,36 \\
\hline Blé & - & - & 77,5 & 76,505 & 76,595 & 23,35 \\
\hline Maïs & 30 & 71 & - & - & - & 18,27 \\
\hline Tourteau de soja & - & - & 4 & 8 & 14 & 20 \\
\hline Tourteau d'arachide & 11,3 & 13,5 & 8 & 8 & 2 & - \\
\hline Son de blé & - & - & - & - & - & 7 \\
\hline Mélasse de canne & 3 & 3,3 & 3 & 3 & 3 & 3 \\
\hline Mélange acides aminés & $4,2^{\mathrm{a}}$ & $4,2^{b}$ & $3,95^{c}$ & $0,38^{d}$ & $0,29^{\mathrm{e}}$ & \\
\hline Mélange minéral et vitaminique ${ }^{f}$ & 3,5 & 4,0 & 3,55 & 4,115 & 4,115 & 4,02 \\
\hline Total & 100 & 100 & 100 & 100 & 100 & 100 \\
\hline
\end{tabular}

a Dans le régime témoin 1, L-lysine $\mathrm{HCl}, 0,51$; L-thréonine, 0,$10 ;$ L-tryptophane, 0,04 ; DL-méthionine, 0,05; L-glutamate monosodique, 3,3; amidon de maïs, 0,2 . L-lysine $\mathrm{HCl}: 0,41$ et 0,305 dans les régimes 2 et 3 . L-thréonine :0,05 et 0 dans les régimes 4 et 5 . L-tryptophane : 0,02 et 0 dans les régimes 6 et 7 . Les retraits d'acides aminés sont assurés en ajoutant de l'amidon de mais tandis qu'un apport variable de glycine permet d'égaliser les teneurs en $\mathrm{N}: 0-$ $0,08-0,15-0,03-0,06-0,015$ et 0,025 dans les régimes 1 à 7 . b Dans le régime témoin $1, \mathrm{~L}$-lysine $\mathrm{HCl}, 0,50 ; \mathrm{L}-$ thréonine, 0,08; L-tryptophane, 0,04; DL-méthionine, 0,05 ; L-glutamate monosodique, 3,3; amidon de maïs, 0,23 . L-tryptophane : 0,02 et 0 dans les régimes 2 et 3 . Les retraits de tryptophane sont opérés en ajoutant de l'amidon de maïs tandis qu'un apport de glycine permet d'égaliser les teneurs en $N: 0,01$ et 0,02 respectivement dans les régimes 2 et 3. c Dans le régime de base 1 à $0,39 \%$ de thréonine, L-lysine $\mathrm{HCL}, 0,45$; L-tryptophane, 0,02; DLméthionine, 0,03 ; glycine, 0,15 ; amidon de maîs, 0,235 . La L-thréonine est ajoutée à doses croissantes dans les autres régimes 2 à 6 : respectivement $0,05-0,10-0,15-0,20$ et $0,25 \%$. Un apport variable de glycine permet d'égaliser les teneurs en $\mathrm{N}: 0,12-0,09-0,06-0,03$ et 0 dans les régimes 2 à 6 . d Dans le régime témoin $1, L$-lysine, 0,28 ; glycine, 0,10 . L-lysine $\mathrm{HCl}: 0,28$ et 0,13 respectivement dans les régimes $1,2,3$ et $4,5,6$. L-thréonine, $0-0,075$ et 0,15 respectivement dans les régimes $1-4,2-5$ et 3-6. Un apport variable de glycine permet d'égaliser les teneurs en $\mathrm{N}: 0,10-0,05-0-0,25-0,20$ et 0,15 dans les régimes 1 à 6 . e Dans le régimes témoin 1 , L-lysine, 0,$19 ;$ glycine, 0,10 . L-lysine $\mathrm{HCl}: 0,19$ et 0 respectivement dans les régimes $1,2,3$ et $4,5,6$. L-thréonine $0-0,08$ et 0,16 dans les régimes $1-4,2-5$ et 3-6. Un apport variable de glycine permet d'égaliser les teneurs en $N: 0,10-0,05-0-0,25-$ 0,20 et 0,15 dans les régimes 1 à 6 . ' Phosphate bicalcique, 2,2-2,5-2,0 et 2,2 respectivement dans les expériences $1,2,3$ et $4-5$. Craie broyée, $1,2-1,4$ et 1,2 respectivement dans les expériences 1,2 et $3-5$. Sel marin, 0,5 dans les expériences 4-5. Mélange oligo-éléments $(0,1)$ et vitamines $(0, \uparrow 15)$, selon Sève et al (1993). Régime finition : phosphate bicalcique, 1,7 ; craie broyée, 1,7 ; sel marin, 0,45 ; mélange oligo-éléments, 0,04 ; mélange vitaminique, 0 ,13. Oligo-éléments, $\mathrm{mg} / \mathrm{kg}$ de régime : sulfate de zinc, $7 \mathrm{H}_{2} \mathrm{O}, 350$; sulfate de manganèse, 50 ; sulfate de cuivre, $5 \mathrm{H}_{2} \mathrm{O}, 20$; iodure de potassium, 0,4 ; sulfate de cobalt, 0,4 . Vitamines, UI ou mg/kg : vit A, $5000 \mathrm{UI}$; vit D3, $1000 \mathrm{UI}$; vit $\mathrm{E}, 10 \mathrm{Ul}$; vit $\mathrm{K} 3,2 \mathrm{mg}$; thiamine, $1 \mathrm{mg}$; riboflavine, $4 \mathrm{mg}$; acide nicotinique, $15 \mathrm{mg}$; pantothénate de calcium, 10 $\mathrm{mg}$; vit B6, $1 \mathrm{mg}$; vit B12, $30 \mathrm{mg}$; acide folique, $1 \mathrm{mg}$; biotine, $0,2 \mathrm{mg}$; choline, $500 \mathrm{mg}$.

dosage par chromatographie liquide sur colonnes échangeuses d'ions, y compris pour le tryptophane dans l'expérience 2.

La consommation d'aliment (en g) par $\mathrm{kg}$ de poids métabolique (poids vif (PV), $\mathrm{kg}^{0,75}$ ) pendant la période expérimentale est calculée suivant la formule proposée par Foster et al (1983) et De Haer et al (1993), en supposant un accroissement linéaire du poids vif entre le début et la fin de la période : poids métabolique moyen, $\mathrm{PV} 0,75$, $\mathrm{kg}=(\mathrm{PVf} 1,75-\mathrm{PVi} 1,75) / 1,75$ * $(\mathrm{PVf}-\mathrm{PVi}), \mathrm{PV} \mathrm{i}$ et $P V f$ étant respectivement les poids vifs au début et à la fin de la période.

\section{Expérience 1}

Cent douze porcs, d'un poids vif moyen initial de $17,6 \pm 1,4 \mathrm{~kg}$ et âgés de $56 \mathbf{j}$, sont répartis entre 
7 traitements, à raison de 8 répétitions pour chacun des 2 sexes. Par rapport à un régime témoin 1 apportant les acides aminés en quantités optimales pour la croissance $(0,82 \%$ de lysine, $0,54 \%$ de thréonine et $0,17 \%$ de tryptophane), suivant les recommandations de I'INRA (1984), on abaisse de 10 et $20 \%$ respectivement les teneurs en lysine (traitements 2 et 3 ), en thréonine (traitements 4 et 5 ) et en tryptophane (traitements 6 et 7 ). Un régime de base contenant $16 \%$ de MAT est formulé de façon à apporter les quantités minimales de chacun des 3 acides aminés étudiés : $0,40 \%$ de lysine, $0,40 \%$ de thréonine et $0,13 \%$ de tryptophane. Il est à base de maïs, blé, tourteau d'arachide, et contient une source d'azote non essentiel sous la forme de L-glutamate monosodique. Les régimes expérimentaux sont obtenus à partir du régime de base à l'aide d'apports des acides aminés sous forme libre: L-lysine $\mathrm{HCl}$, L-thréonine et L-tryptophane.

\section{Expérience 2}

Compte tenu des résultats de l'expérience 1 , ne faisant apparaître qu'une légère diminution de la croissance à la suite d'une réduction du taux de tryptophane de 0,17 à $0,14 \%$, il a été procédé à l'application d'une déficience plus sévère en cet acide aminé. Trois taux sont ainsi utilisés $(0,10-$ 0,12 et $0,14 \%$ ) dans un essai comprenant 60 animaux d'un poids vif moyen initial de 18,5 $\pm 0,4$ $\mathrm{kg}$ et $55 \mathrm{j}$ d'âge, à raison de 10 répétitions par traitement et par sexe. Les régimes, à base de maiss et de tourteau d'arachide, renferment $16 \%$ de MAT. Ils bénéficient d'une supplémentation en L-lysine $\mathrm{HCl}$ et L-thréonine, ainsi que d'un apport complémentaire d'azote non indispensable sous forme de L-glutamate monosodique. L'apport de L-tryptophane permet de faire varier la teneur en cet acide aminé à partir d'un taux basal de $0,10 \%$. L'expérience est poursuivie jusqu'à des poids finaux aussi comparables que possible, compte tenu de la difficulté de maintenir plus longuement les animaux sur les régimes carencés en tryptophane.

\section{Expérience 3}

Six taux de thréonine régulièrement espacés, entre 0,39 et $0,64 \%$, font l'objet d'une comparaison chez 120 porcs d'un poids vif moyen initial de $21,5 \pm 1,0 \mathrm{~kg}$ et 70 j d'âge, à raison de 10 répétitions par traitement et par sexe. Ils correspondent à l'addition de doses croissantes de L-thréo- nine à un régime à base de blé, tourteau de soja et tourteau d'arachide, renfermant en moyenne $15,9 \%$ de MAT et $0,87 \%$ de lysine. En dehors de la thréonine, les teneurs en acides aminés des régimes sont conformes aux recommandations (INRA, 1984).

\section{Expériences 4 et 5}

L'étude de l'influence d'un excès relatif de thréonine par rapport à la lysine (acide aminé limitant primaire) sur le niveau d'ingestion alimentaire et les performances de croissance a fait l'objet de 2 essais complémentaires (expériences 4 et 5 ).

Dans l'expérience 4,60 porcs d'un poids vif moyen de $21,3 \pm 1,2 \mathrm{~kg}$ et âgés de $51 \mathrm{j}$, sont répartis entre 6 traitements, à raison de 5 répétitions par traitement et par sexe, suivant un plan factoriel avec 2 taux de lysine (un taux optimal de $0,83 \%$ et un taux réduit de $15 \%$, soit $0,71 \%$ ) et 3 taux de thréonine $(0,51,0,58$ et $0,65 \%$, soit respectivement 15 et $30 \%$ au dessus du taux basal). Les 6 régimes sont composés à partir d'un même régime de base (blé-tourteau de sojatourteau d'arachide) apportant $16 \%$ de MAT, avec une supplémentation en L-lysine et L-thréonine.

Dans l'expérience 5, le taux de thréonine est porté de 0,51 à $0,53 \%$. Les 3 taux de thréonine s'élèvent ainsi à $0,53,0,61$ et $0,69 \%$, pour 0,86 et $0,71 \%$ de lysine, dans des régimes renfermant en moyenne $16,6 \%$ de MAT. L'essai est réalisé sur 120 porcs d'un poids vif moyen initial de $19,9 \pm 0,65 \mathrm{~kg}$ et d'un âge moyen de $65 \mathrm{j}$, à raison de 10 répétitions par traitement et par sexe.

\section{Période de finition et observations à l'abattage}

À l'issue de la période expérimentale, les animaux, dans chacune des expériences, reçoivent un même aliment renfermant $17 \%$ de MAT, $0,85 \%$ de lysine et 12,5 MJ d'énergie digestible par kg d'aliment frais. Ce dernier, qui correspond à un aliment unique standard utilisé pendant la totalité de l'engraissement, est composé d'un mélange de céréales (orge, blé et maïs), de tourteau de soja et de son de blé, et est présenté sous forme de granulés de $5 \mathrm{~mm}$ de diamètre (tableau II). Les contrôles périodiques de composition font ressortir une teneur moyenne en matière sèche de $87,9 \pm 1,3 \%$ et en MAT de $17,4 \pm 0,7 \%$. Les femelles et les mâles castrés 
Tableau II. Plan de rationnement alimentaire.

$\begin{array}{cc}\begin{array}{c}\text { Intervalle de poids vif } \\ (\mathrm{kg})\end{array} & \begin{array}{c}\text { Quantité d'aliment/j } \\ (\mathrm{kg})\end{array} \\ & \\ 40-44 & 2,0 \\ 44-48 & 2,1 \\ 48-52 & 2,2 \\ 52-56 & 2,3 \\ 56-60 & 2,4 \\ 60-64 & 2,5 \\ 64-68 & 2,6 \\ 68-72 & 2,7 \\ 72-76^{a} & 2,8 \\ 76-100^{a} & 2,9\end{array}$

a Dans les expériences 3 et $5,72-80: 2,8 ; 80-90$ : 2,$9 ; 90-100: 3,0$.

sont soumis à un même plan de rationnement alimentaire en fonction du poids vif (tableau II), les quantités d'aliment étant légèrement augmentées pendant la phase terminale de l'engraissement dans les expériences 3 et 5 . Ceci revient logiquement à restreindre un peu plus fortement les mâles castrés que les femelles par rapport à leur niveau d'ingestion spontanée, qui est plus élevé. Les résultats de consommation et d'indice de consommation pour la période totale sont donnés en négligeant les écarts de valeur énergétique entre les régimes expérimentaux et le régime de finition.

À un poids vif final avoisinant $100 \mathrm{~kg}$, les animaux sont abattus après un jeûne de $16 \mathrm{~h}$ en moyenne. Sur les carcasses chaudes, on procède aux mesures linéaires de gras et de muscle à l'aide de l'appareil "Fat-O-Meater", en vue de l'estimation des teneurs en muscle et en gras à partir des équations de prédiction établies par Desmoulin et al (1988). Les mesures de gras effectuées concernent les sites $X 1$ (épaisseur sur la fente au niveau du Gluteus Medius), X2 (mesure latérale, à $8 \mathrm{~cm}$ de la fente, au niveau de la jonction entre les $3^{e}$ et $4^{e}$ vertèbres lombaires), $\mathrm{X} 4$ (mesure latérale, à $6 \mathrm{~cm}$ de la fente, entre les $3^{e}$ et $4^{e}$ côtes, comptées à partir de la dernière côte). L'épaisseur du muscle long dorsal X'5 est mesurée au même site que la mesure de gras $X 4$. Les quantités finales de muscle et de gras sont calculées à l'aide de la relation entre le poids de la carcasse chaude et le poids de la carcasse froide sans tête, établie à partir d'expériences contemporaines (tableau III). Les gains journaliers de muscle et de gras sont estimés à partir des quantités correspondantes dans la carcasse et des quantités initiales de tissus estimées selon Karege (1991) chez des animaux du même troupeau expérimental. Les mesures de gras et de muscle sont complétées par l'enregistrement de la longueur de la carcasse, totale (entre l'atlas et le bord antérieur de la symphyse pubienne) et restreinte (entre le bord antérieur de la symphyse pubienne et le milieu de la première côte), à l'exception de l'expérience 2 . Dans l'expérience 2, le $\mathrm{pH}$ ultime ( $24 \mathrm{~h}$ post mortem) a été mesuré dans le muscle long dorsal.

\section{Calculs statistiques}

Le traitement statistique des données expérimentales est effectué en utilisant la procédure du logiciel SAS (1990), avec l'analyse de variance, et dans certains cas l'analyse de covariance (poids des tissus à l'abattage, influence du poids vif à l'issue de la période expérimentale). Après prise en compte de l'effet bloc intra sexe (dispositif en split-plot), l'effet sexe est testé par rapport au carré moyen résiduel entre blocs. Les contrastes sont testés selon des modalités particulières en fonction du dispositif de l'expérience. Ils sont jugés significatifs en dessous du seuil $P<0,10$

\section{RÉSULTATS}

Compte tenu de la similitude de réponse des animaux après une durée constante (42 j) ou à un même poids vif, au cours de la période expérimentale, seuls sont présentés les résultats obtenus sur la totalité de cette dernière. Dans l'ensemble, l'influence du sexe reproduit les différences observées habituellement entre femelles et mâles castrés. Pendant la phase de finition, alors que les animaux sont soumis à un même plan de rationnement alimentaire en fonction du poids vif, les femelles ont une croissance supérieure à celle des mâles castrés et leur indice de consommation est plus faible, en relation avec une adiposité des carcasses 
moins importante et une teneur en muscle plus élevée. De plus, dans les expériences 4 et 5 , elles présentent une longueur de la carcasse plus élevée.

\section{Expérience 1}

En l'absence d'interaction entre les traitements et le type sexuel, les résultats (tableau III) sont présentés globalement pour les femelles et les mâles castrés. Les données concernant la période expérimentale ont fait l'objet d'une publication antérieure (Henry, 1983).

\section{Réduction du taux de lysine}

La réduction du taux de lysine de 0,79 à 0,71 et $0,63 \%$ (respectivement -10 et $-20 \%$ par rapport au niveau témoin), pendant la période expérimentale (18-47 $\mathrm{kg}$ de poids vif), entraîne une diminution linéaire de la vitesse de croissance $(-13 \%$ entre les taux extrêmes : $P<0,01$ ). Les variations de la consommation journalière d'aliment font apparaître une réponse quadratique $(P<$ 0,10 ), la consommation étant augmentée au taux sub-optimal de lysine. II s'ensuit un accroissement de l'indice de consommation.

Les performances enregistrées pendant la phase de finition (gain moyen journalier, indice de consommation), avec l'application d'un même régime et d'un même plan de rationnement, ne sont pas modifiées par les conditions d'alimentation antérieures. On observe cependant une tendance à un accroissement du gain moyen journalier après une période de forte restriction en lysine $(-20 \%)$, en relation avec une consommation d'aliment accrue $(P<0,05)$.

Sur l'ensemble de l'expérience, la vitesse de croissance et l'indice de consommation ne sont pas affectés significativement par une déficience initiale du régime en lysine. On note seulement une tendance à une diminution des performances, en relation avec leur réduction initiale.

L'effet majeur observé à l'abattage consiste dans un accroissement du dépôt journalier de gras $(P<0,05)$. L'épaisseur de muscle $\left(X^{\prime} 5\right)$ est réduite après une déficience prononcée en lysine $(-20 \%$ : effet quadratique à $P<0,10$ ). Cette réponse est associée à une augmentation de la longueur de la carcasse (totale et restreinte : $P<$ $0,05)$ consécutivement à une déficience sévère en lysine.

\section{Réduction du taux de thréonine}

Comme pour la lysine, un apport restreint de thréonine en dessous de $0,54 \%$ à partir de $18 \mathrm{~kg}$ de poids vif retentit défavorablement sur le gain moyen journalier $(-12 \%$ pour $0,44 \%$ de thréonine : $P<0,01)$. La quantité d'aliment consommée/kg PV 0,75 après 42 j d'expérience est augmentée à un taux sub-optimal de thréonine (135 et $134 \mathrm{~g}$ respectivement pour -10 et $-20 \%$ de thréonine, contre $129 \mathrm{~g}$ pour le témoin : $P<$ $0,10)$. En même temps, l'indice de consommation est accru $(P<0,01)$.

Pendant la phase de finition, les performances ne sont pas modifiées. On retrouve l'effet dépressif d'une déficience initiale en thréonine sur la croissance à l'issue de la période totale $(P<0,05$ et $P<0,10$, respectivement pour le gain de poids vif et l'indice de consommation).

À l'abattage, on observe une augmentation du rendement de la carcasse $(P<0,10)$ à la suite d'une déficience en thréonine. La longueur des carcasses n'est pas affectée. Le résultat le plus net est représenté par un effet quadratique d'une déficience initiale en thréonine sur les critères d'adiposité. Ainsi, les épaisseurs de gras $X 1$ et $X 4$ sont accrues au taux sub-optimal de thréonine (respectivement $P<0,10$ et $P<0,05$ ). II en est de même du pourcentage et du dépôt journalier de gras $(P<0,10)$, tandis que le pourcentage de muscle est abaissé $(P<$ 


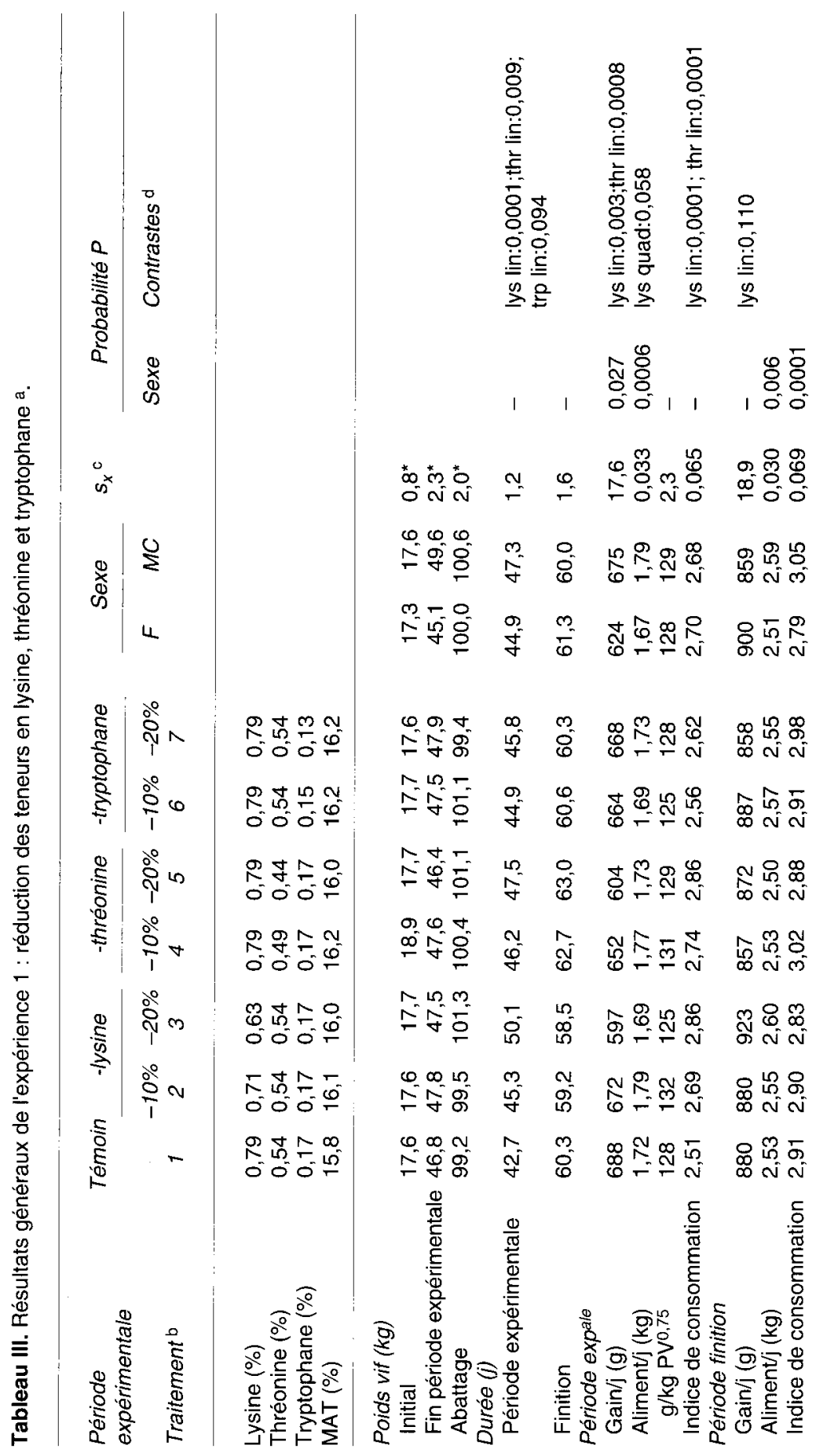




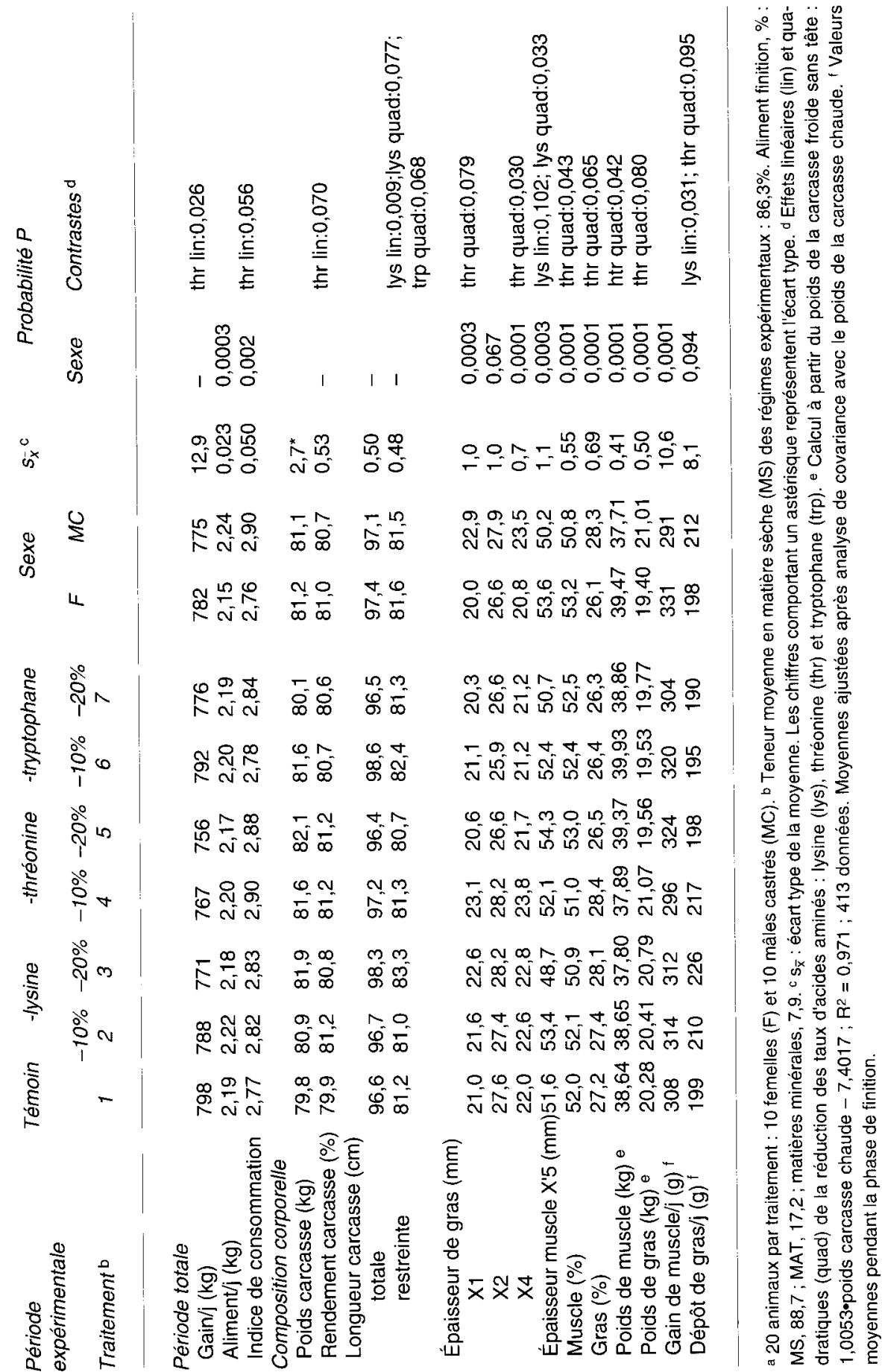


$0,05)$. Après analyse de covariance utilisant comme covariable le poids de la carcasse chaude, les poids de muscle et de gras ajustés à l'abattage sont respectivement plus faible et plus élevé au taux sub-optimal de thréonine (effet quadratique respectivement à $P<0,05$ et $P<0,10)$.

\section{Réduction du taux de tryptophane}

Une diminution du taux de tryptophane de 0,17 à $0,13 \%$ entre 18 et $47 \mathrm{~kg}$ de poids vif n'affecte pas significativement la vitesse de croissance, la consommation d'aliment et l'indice de consommation. On relève seulement une tendance à une réduction du gain moyen journalier de $3 \%$. Ceci explique l'absence de différence entre traitements pendant la phase de finition et sur l'ensemble de l'expérience.

Les observations à l'abattage font apparaître un effet quadratique d'une réduction initiale du taux de tryptophane sur la longueur totale $(P<0,01)$ et restreinte $(P<$ $0,10)$ de la carcasse, celle-ci étant plus élevée au taux sub-optimal de tryptophane $(0,15 \%)$.

\section{Expérience 2}

L'absence d'interaction entre les traitements et le sexe ont permis de regrouper les résultats pour les femelles et les mâles castrés.

L'abaissement du taux de tryptophane de 0,14 à $0,10 \%$ à partir de $18,5 \mathrm{~kg}$ de poids vif (tableau IV) provoque une très forte dépression de la croissance $(-50 \%)$ pendant les 42 j d'expérience. Cette durée a été prolongée dans les lots carencés en tryptophane, de manière à égaliser les poids vifs au début de la période de finition. En réalité, en raison de refus d'aliment importants, la période expérimentale a dû être interrompue dans le traitement 3 , pour un poids vif final se situant respectivement à 45,44 et $38,6 \mathrm{~kg}$ dans les traitements 1 , 2 et 3 . Du fait d'un gaspillage d'aliment inhabituel dans les lots déficients en tryptophane, les quantités d'aliment ingéré n'ont pas été prises en compte. Sur la totalité de la période expérimentale, le gain moyen journalier était abaissé de $42 \%(P<0,01)$. La mesure de l'épaisseur du lard aux ultrasons à la fin de cette période fait ressortir une diminution au niveau du cou, site au développement le plus précoce parmi les trois étudiés $(P<0,01)$ : respectivement $15,8,13,4$ et $12,4 \mathrm{~mm}$ dans les traitements 1,2 et 3 .

Pendant la phase de finition, alors que les animaux sont soumis à une même alimentation, il n'apparaît aucune différence dans la vitesse de croissance entre traitements, même après analyse de covariance en fonction du poids vif à l'issue de la période expérimentale. L'indice de consommation est abaissé dans les traitements initialement déficitaires en tryptophane $(P<$ $0,01)$. Toutefois, cette différence disparaît après analyse de covariance prenant en compte le poids vif à la fin de la période expérimentale.

Sur la période totale $(18,5-100,6 \mathrm{~kg}$ de poids vif), on retrouve l'effet dépressif d'une déficience initiale en tryptophane $(P<0,01)$, associée à un allongement de la durée d'engraissement, soit respectivement 111,117 et $131 \mathrm{j}$ pour $0,14,0,12$ et $0,10 \%$ de tryptophane.

Les observations à l'abattage font ressortir une diminution des épaisseurs de gras aux sites X1 $(P<0,05), \mathrm{X} 2(P<0,05)$ et X4 $(P<0,01)$. L'épaisseur de muscle $X^{\prime} 5$ est également abaissée au taux le plus bas de tryptophane $(0,10 \%: P<0,10)$. Le pourcentage de muscle dans la carcasse est augmenté dans les traitements initialement déficitaires en tryptophane $(P<0,05)$. II en est de même du poids final de muscle $(P<$ 0,05 , après covariance sur le poids de la carcasse chaude) et du gain journalier de muscle $(P<0,10)$, tandis que le poids final 
Tableau IV. Résultats généraux de l'expérience 2 : réduction de la teneur en tryptophane a.

\begin{tabular}{|c|c|c|c|c|c|c|c|c|c|}
\hline \multirow[t]{3}{*}{ Traitement $\mathrm{b}$} & \multirow[t]{3}{*}{1} & \multirow[t]{3}{*}{2} & \multirow[t]{3}{*}{3} & \multicolumn{2}{|r|}{ Sexe } & $s_{\bar{x}}^{c}$ & \multicolumn{3}{|c|}{ Probabilité $P$} \\
\hline & & & & \multirow[t]{2}{*}{$F$} & \multirow[t]{2}{*}{$M$} & & \multirow[t]{2}{*}{ Sexe } & \multicolumn{2}{|c|}{ Contrastes $^{\mathrm{d}}$} \\
\hline & & & & & & & & Trp lin & 1 vs $2-3$ \\
\hline Tryptophane (\%) & 0,14 & 0,12 & 0,10 & & & & & & \\
\hline MAT $(\%)$ & 15,8 & 16,1 & 16,0 & & & & & & \\
\hline \multicolumn{10}{|l|}{ Poids vif $(\mathrm{kg})$} \\
\hline Initial & 18,5 & 18,5 & 18,5 & 18,0 & 18,9 & $0,4^{\star}$ & & & \\
\hline Fin période expérimentale & 45,0 & 44,4 & 38,6 & 40,6 & 44,7 & $3,9^{*}$ & & & \\
\hline Abattage & 101,0 & 100,9 & 100,0 & 100,4 & 100,8 & $2,1^{\star}$ & & & \\
\hline \multicolumn{10}{|l|}{ Durée (j) } \\
\hline Période expérimentale & 42,8 & 50,2 & 56,1 & 50,3 & 49,0 & 0,7 & - & 0,0001 & 0,0001 \\
\hline Finition & 68,0 & 66,9 & 75,1 & 71,1 & 68,9 & 1,2 & - & 0,0002 & 0,045 \\
\hline \multicolumn{10}{|l|}{ Période exple } \\
\hline $\begin{array}{l}\text { Gain/j }(\mathrm{g}) \\
\text { Épaisseur de lard }(\mathrm{mm})\end{array}$ & 620 & 521 & 359 & 461 & 539 & 16,4 & 0,0007 & 0,0001 & - \\
\hline Rein & 12,8 & 12,2 & 12,5 & 12,4 & 12,6 & 0,48 & - & - & - \\
\hline Dos & 9,2 & 8,7 & 8,6 & 8,5 & 9,1 & 0,29 & 0,062 & - & - \\
\hline Cou & 15,8 & 13,4 & 12,4 & 13,6 & 14,1 & 0,54 & - & 0,0001 & 0,0001 \\
\hline \multicolumn{10}{|l|}{ Période finition } \\
\hline Gain/j (g) & 824 & 833 & 821 & 845 & 807 & 13,4 & 0,020 & - & - \\
\hline Aliment/j (kg) & 2,54 & 2,47 & 2,42 & 2,45 & 2,50 & 0,020 & 0,028 & - & - \\
\hline Ind consom & 3,09 & 2,99 & 2,96 & 2,92 & 3,11 & 0,045 & 0,0043 & 0,035 & 0,043 \\
\hline \multicolumn{10}{|l|}{ Période totale } \\
\hline Gain/j & 745 & 706 & 622 & 683 & 700 & 8,3 & 0,105 & 0,0001 & 0,0001 \\
\hline \multicolumn{10}{|l|}{ Composition corporelle } \\
\hline Poids carcasse $(\mathrm{kg})$ & 81,5 & 81,4 & 81,3 & 81,4 & 81,3 & $2,0^{*}$ & & & \\
\hline Rendement carcasse (\%) & 80,7 & 80,7 & 81,3 & 81,1 & 80,7 & 0,35 & - & - & - \\
\hline \multicolumn{10}{|l|}{ Épaisseur de gras $(\mathrm{mm})$} \\
\hline$\times 1$ & 24,9 & 20,1 & 19,4 & 19,7 & 23,2 & 0,79 & - & 0,016 & 0,047 \\
\hline$\times 2$ & 25,8 & 24,7 & 24,0 & 23,5 & 26,2 & 0,66 & 0,018 & 0,026 & 0,08 \\
\hline$\times 4$ & 22,3 & 21,0 & 20,5 & 20,2 & 22,3 & 0,65 & 0,023 & 0,0079 & 0,040 \\
\hline \multicolumn{10}{|l|}{ Épaisseur de muscle } \\
\hline$X^{\prime} 5(\mathrm{~mm})$ & 52,1 & 53,7 & 49,9 & 51,7 & 52,2 & 0,88 & - & 0,074 & - \\
\hline Muscle (\%) & 50,6 & 51,7 & 51,5 & 51,9 & 50,6 & 0,39 & 0,022 & 0,045 & 0,058 \\
\hline Gras (\%) & 26,9 & 25,6 & 25,1 & 24,9 & 26,8 & 0,53 & 0,024 & 0,0066 & 0,027 \\
\hline Poids de muscle $\left(\mathrm{kg}^{\mathrm{e}}\right)$ & 37,56 & 38,12 & 38,58 & 38,63 & 37,49 & 0,30 & 0,022 & 0,048 & 0,061 \\
\hline Poids de gras $\left(\mathrm{kg}^{\mathrm{e}}\right)$ & 20,25 & 19,67 & 18,31 & 18,53 & 20,30 & 0,40 & 0,025 & 0,0073 & 0,030 \\
\hline Gain de muscle/j $\left(\mathrm{g}^{f}\right)$ & 277 & 293 & 297 & 300 & 278 & 5,8 & 0,016 & 0,056 & 0,046 \\
\hline Dépôt de gras/j $\left(\mathrm{g}^{f}\right)$ & 189 & 176 & 173 & 172 & 187 & 6,6 & - & 0,016 & 0,062 \\
\hline $\mathrm{pH}_{\mathrm{u}}$ long dorsalg & 5,60 & 5,54 & 5,54 & 5,57 & 5,54 & 0,028 & - & - & - \\
\hline
\end{tabular}

a 20 animaux par traitement : 10 femelles $(F)$ et 10 mâles castrés (MC). ${ }^{b}$ Teneur moyenne en matière sèche des régimes expérimentaux : $86,0 \%$; matières minérales : $5,8 \%,{ }^{\circ} \mathrm{S}_{\overline{\mathrm{x}}}$ : écart type de la moyenne. Les chiffres comportant un astérisque représentent l'écart type. ${ }^{d}$ Trp lin : effet linéaire de la teneur en tryptophane. 1 vs 2-3: contraste comparant le traitement témoin 1 aux traitements à teneur réduite en tryptophane. e cf tableau III. Moyennes ajustées après analyse de covariance avec le poids de la carcasse chaude. $f$ Valeurs moyennes pendant la phase de finition. $9 \mathrm{pH}$ ultime après $24 \mathrm{~h}$. 
et le dépôt journalier de gras sont diminués (respectivement $P<0,05$ et $P<0,01$ ). La mesure du $\mathrm{pH}$ ultime du muscle long dorsal ne fait apparaître aucune différence entre les traitements.

\section{Expérience 3}

Les résultats se rapportant aux effets de taux variables de thréonine $(0,39$ à $0,64 \%)$ sur la croissance entre 21 et $55 \mathrm{~kg}$ de poids vif ont été détaillés et discutés dans une publication antérieure (Sève et al, 1993). Rapportés ici globalement pour les femelles et les mâles castrés (tableau V), ils indiquent un effet linéaire de la teneur en thréonine sur le gain moyen journalier et l'indice de consommation $(P<0,05)$, avec des performances diminuées aux taux de thréonine les plus faibles $(0,39$ et $0,42 \%)$. La consommation d'aliment par unité de poids métabolique ( $\mathrm{g} / \mathrm{PV}, \mathrm{kg}^{0,75}$ ) n'est pas affectée par la teneur du régime en thréonine. $\mathrm{La}$ mesure de l'épaisseur du lard dorsal aux ultra-sons au niveau du cou fait apparaître un effet quadratique du taux de thréonine $(P<0,05)$. L'épaisseur de lard est plus faible aux taux extrêmes $(0,39$ et $0,64 \%)$, et plus élevée aux taux intermédiaires $(0,44$ à $0,59 \%$ ).

Pendant la phase de finition, on enregistre un effet linéaire du taux antérieur de thréonine sur la vitesse de croissance $(P<$ $0,05)$ et l'indice de consommation $(P<0,05)$, avec un gain pondéral plus élevé et un indice de consommation plus faible chez les animaux ayant reçu le taux le plus faible de thréonine. Sur la totalité de l'expérience, on n'observe pas de différence entre les traitements initiaux.

Les résultats à l'abattage ne montrent aucun effet du taux initial de thréonine sur la longueur des carcasses ni sur les mesures linéaires de gras, à l'exception d'un effet quadratique de la thréonine sur l'épaisseur X1 (plus faible chez les ani- maux ayant reçu la plus faible dose de thréonine : $P<0,05)$. De la même façon, l'augmentation du taux de thréonine en début de croissance exerce un effet quadratique sur le poids final de gras $(P<$ $0,10)$, plus faible aux taux extrêmes de thréonine.

\section{Expériences 4 et 5}

Dans les 2 expériences 4 et 5, on n'observe pas d'interaction entre les traitements et le sexe au niveau des critères de croissance. Les variations combinées des teneurs en lysine et en thréonine (tableau VI et VII) font ressortir une interaction entre la thréonine (terme linéaire) et la lysine sur l'ingestion alimentaire, par jour $(P<0,10)$ ou par unité de poids métabolique $(\mathrm{g} / \mathrm{kg} P V 0,75: P<$ $0,05)$. Au taux optimal de lysine $(0,83 \%)$, dans l'expérience 4 , la consommation d'aliment augmente avec le rapport thréonine/lysine au dessus de 0,61 , tandis qu'au taux réduit de lysine $(0,71 \%)$ elle diminue lorsqu'augmente le rapport thréonine/lysine au dessus de 0,72. La vitesse de croissance est affectée négativement par la réduction de la teneur en lysine $(P<0,05)$, et l'indice de consommation est augmenté $(P<0,01)$. Dans l'expérience 5, une accentuation de l'excès de thréonine par rapport à la lysine provoque une diminution de la consommation d'aliment (interaction à $P<0,05$ ). Globalement, une réduction du taux de lysine entraîne une augmentation de l'indice de consommation $(P<0,01)$.

L'épaisseur de lard à la fin de la période expérimentale (51 kg de poids vif) est acrue à la suite d'une réduction de la teneur en lysine de 0,83 ou $0,86 \%$ à $0,71 \%$ : de 8,4 à $9,1 \mathrm{~mm}(P<0,05)$ au niveau du dos, dans l'expérience 4 ; de 18,4 à $19,6 \mathrm{~mm}$ au rein, de 12,0 à $14,2 \mathrm{~mm}$ au dos $(P<0,01)$, et de 24,3 à $28,7 \mathrm{~mm}$ au cou $(P<0,01)$, dans l'expérience 5 . Dans l'expérience 4 , on note, au niveau du rein, une interaction entre la 
thréonine (terme linéaire) et la lysine $(P<$ $0,05)$ : l'épaisseur du lard diminue au taux sub-optimal de lysine à mesure que l'excès relatif de thréonine s'accentue.

En finition, dans l'expérience 4, lorsque les animaux sont soumis aux mêmes conditions d'alimentation, on n'observe aucun effet du déséquilibre initial thréonine/lysine sur le gain moyen journalier. En revanche, il apparaît une interaction thréonine $x$ lysine sur l'indice de consommation. Ce dernier est accru dans le traitement $3(0,82 \%$ de lysine et $0,65 \%$ de thréonine), tandis qu'il est plus faible dans le traitement 6 (au bas taux de lysine et pour le rapport thréonine/lysine le plus élevé). Dans l'expérience 5 , les animaux ayant reçu antérieurement un régime déficient en lysine ont une croissance améliorée de $3 \%(P<0,10)$, tandis que l'indice de consommation est également abaissé dans la même proportion $(P<$ $0,10)$.

Sur la totalité de l'étude $(20-100 \mathrm{~kg}$ de poids vif), dans l'expérience 4 , en dehors de l'interaction thréonine $x$ lysine sur la consommation d'aliment $(P<0,05)$, on ne retrouve aucun effet significatif sur la croissance et l'efficacité alimentaire. Dans l'expérience 5 , la vitesse de croissance est plus faible $(-3 \%: P<0,10)$ après une réduction de la teneur en lysine entre 20 et $51 \mathrm{~kg}$. Le gain moyen journalier est également abaissé consécutivement à un apport excessif de thréonine au taux sub-optimal de lysine $(P<$ $0,10)$. L'interaction thréonine $x$ lysine sur la consommation d'aliment est le reflet de celle observée pendant la période expérimentale.

L'analyse des résultats à l'abattage, dans l'expérience 4, ne fait ressortir aucune interaction entre les traitements et le sexe. On observe un effet quadratique de la thréonine sur la longueur de la carcasse (totale et restreinte : $P<0,05)$, dans le sens d'une augmentation de la longueur pour le rapport thréonine/lysine intermédiaire, et notamment au taux optimum de lysine. On note surtout une interaction thréonine (terme linéaire) $x$ lysine sur les épaisseurs de gras $\mathrm{X} 1, \mathrm{X} 2$ et X4 (respectivement $P<0,01, P<$ $0,05$ et $P<0,05)$. Celles-ci augmentent et diminuent respectivement aux taux optimal et sub-optimal de lysine lorsqu'on ajoute de la thréonine. L'épaisseur de muscle X'5 est influencée favorablement par le taux supérieur de lysine. L'effet quadratique de la thréonine s'explique notamment par une épaisseur de maigre réduite en présence d'un excès de thréonine au taux sub-optimal de lysine. L'interaction thréonine $x$ lysine est encore observée au niveau des poids de muscle et de gras (après covariance sur le poids de la carcasse chaude : $P<0,10$ et $P<0,01$ ), de même qu'au niveau des pourcentages de muscle $(P<0,10)$ et de gras $(P<0,01)$, et des gains de muscle $(P<0,05)$ et de gras $(P<0,10)$. D'une façon générale, l'adiposité des carcasses est accentuée au taux optimal de lysine lorsqu'augmente l'apport de thréonine, tandis que l'inverse a lieu au taux sub-optimal de lysine. De même, le poids final de muscle, comme le gain journalier de muscle, diminue à mesure qu'augmente le rapport thréonine/lysine au taux optimal de lysine $(0,82 \%)$, tandis qu'au taux sub-optimal de lysine $(0,70 \%)$ il augmente avec l'excès de thréonine relativement à la lysine.

Dans l'expérience 5, l'examen des résultats à l'abattage fait apparaître, à la différence de l'expérience précédente, une interaction traitements $x$ sexe pour la plupart des critères. Celle-ci s'explique glóbalement par le fait qu'un apport excessif de thréonine pour un taux sub-optimal de lysine se traduit, chez les mâles castrés, par une diminution du dépôt de muscle et une augmentation du dépôt gras, alors que chez les femelles on observe une tendance inversée. L'effet constaté sur la longueur de la carcasse est caractérisé par une interaction thréonine (terme linéaire) $x$ lysine $(P<$ $0,05)$. La longueur de la carcasse diminue avec l'élévation du rapport thréonine $x$ lysine 


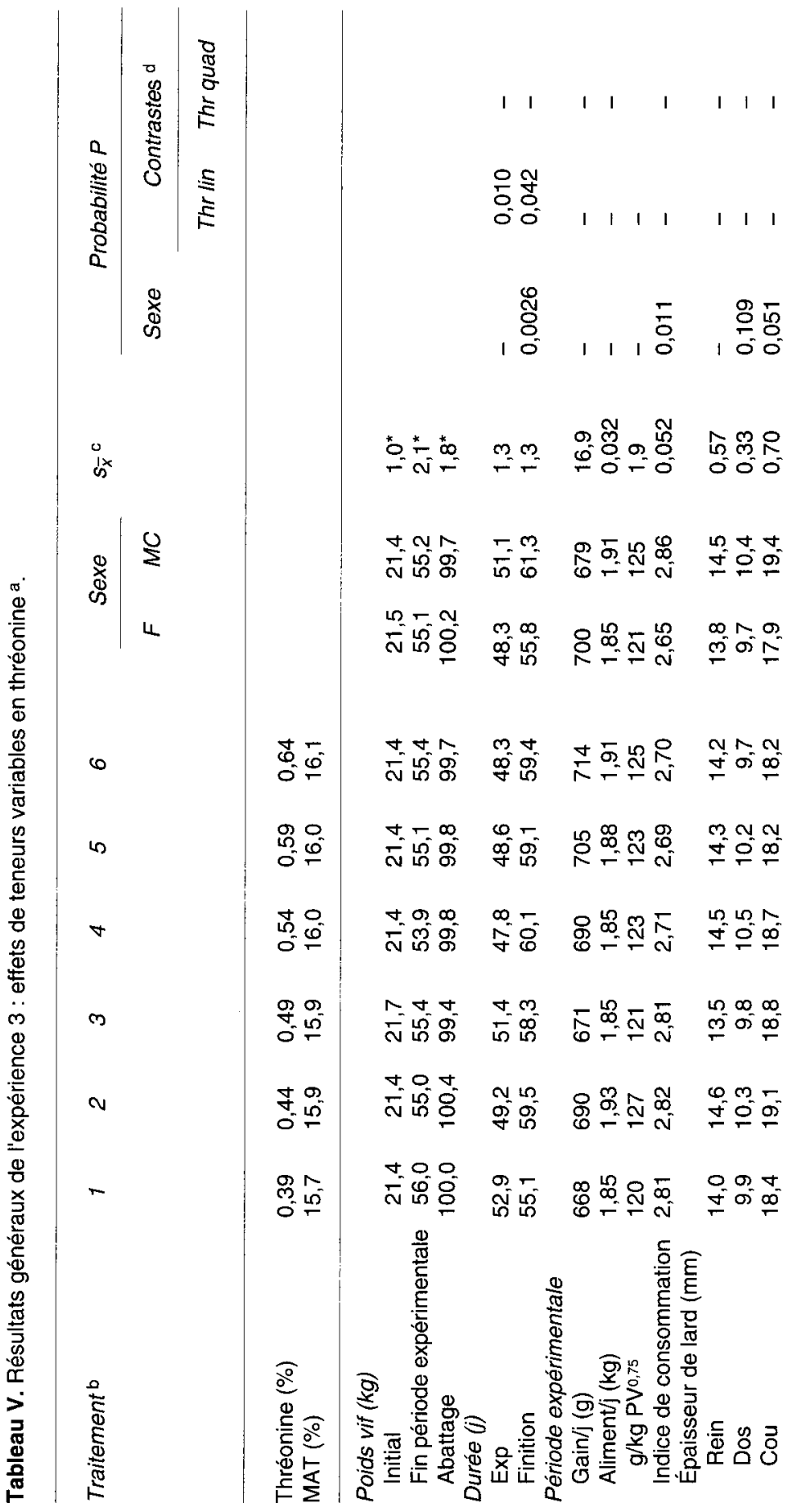




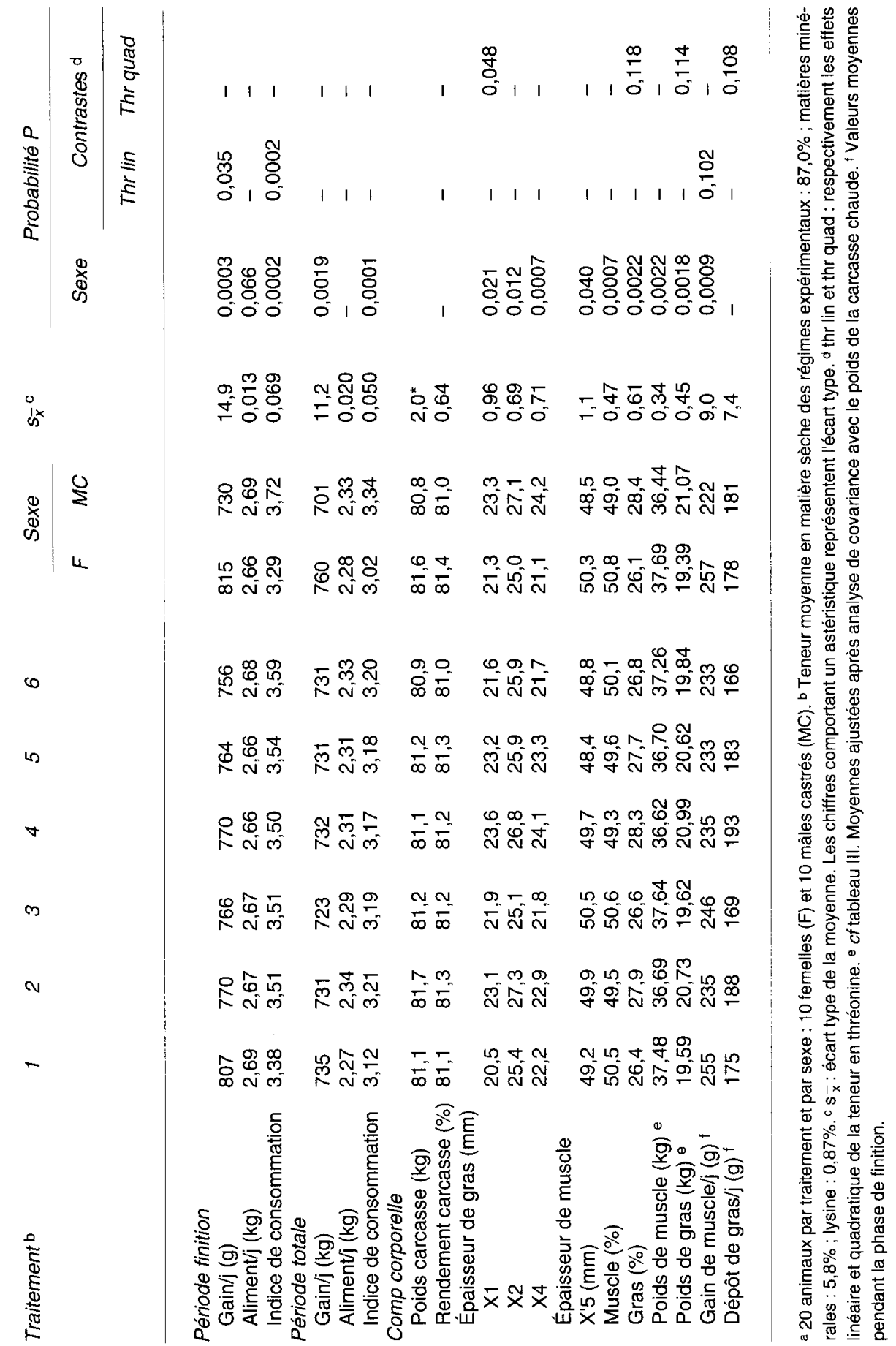




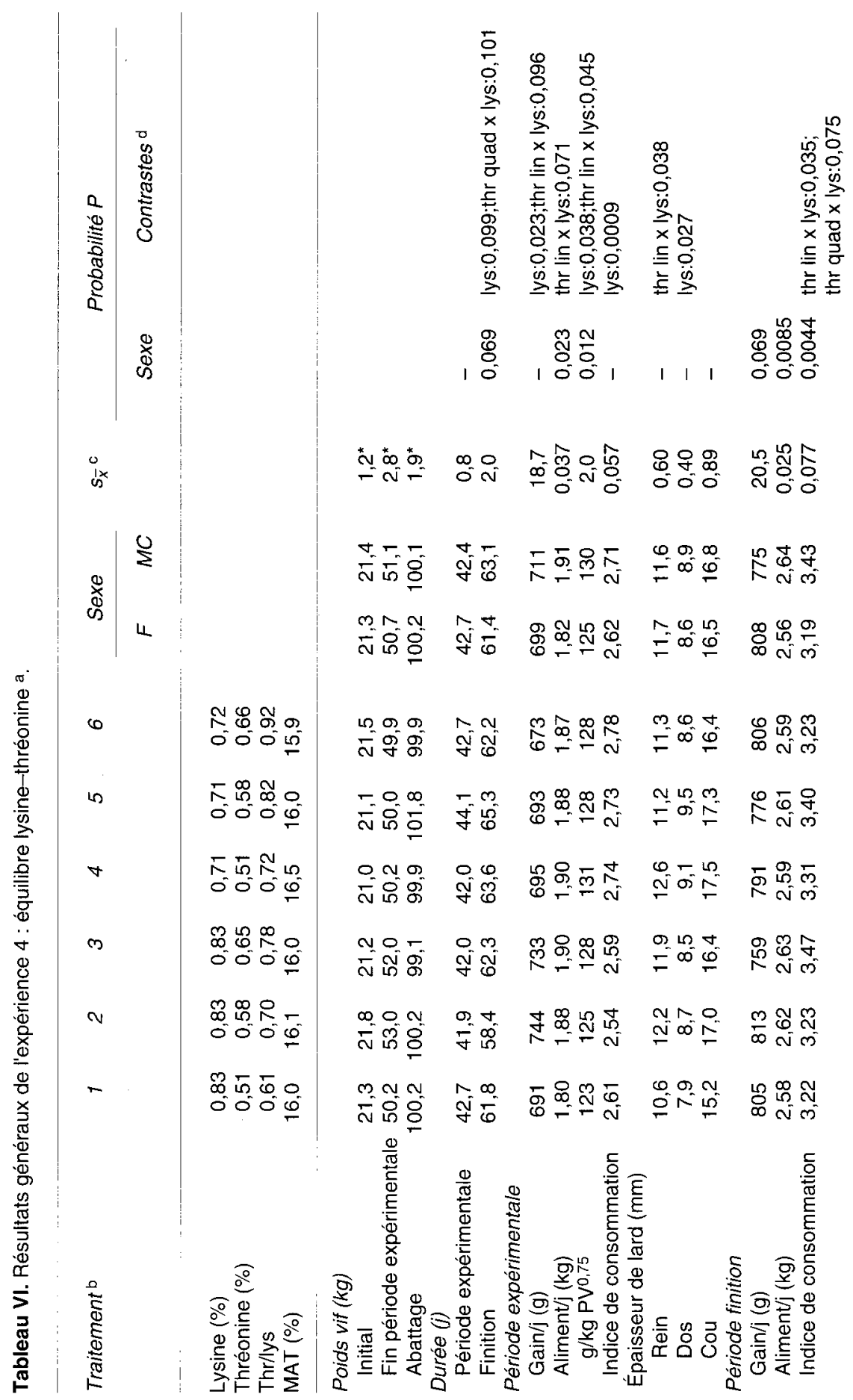




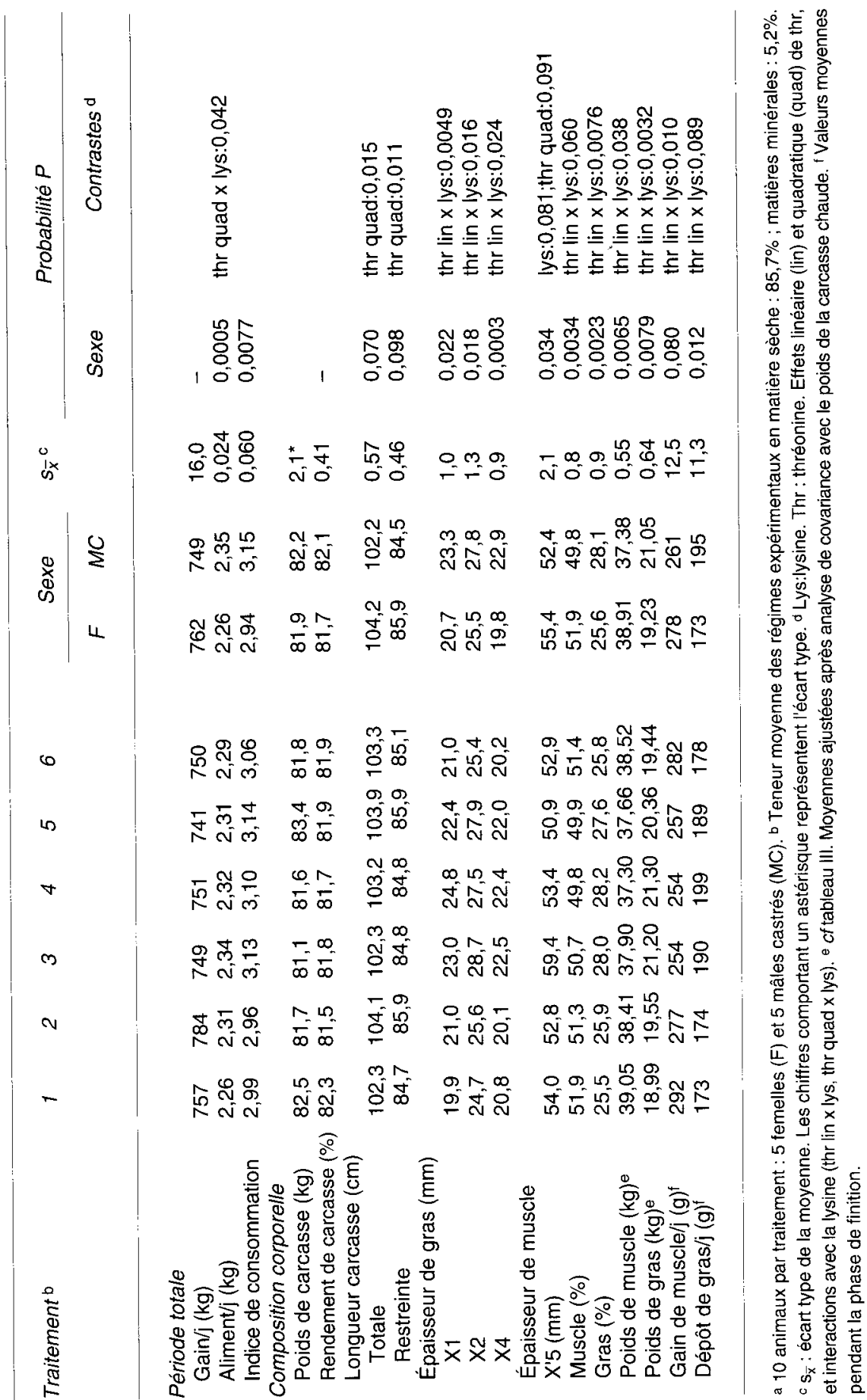




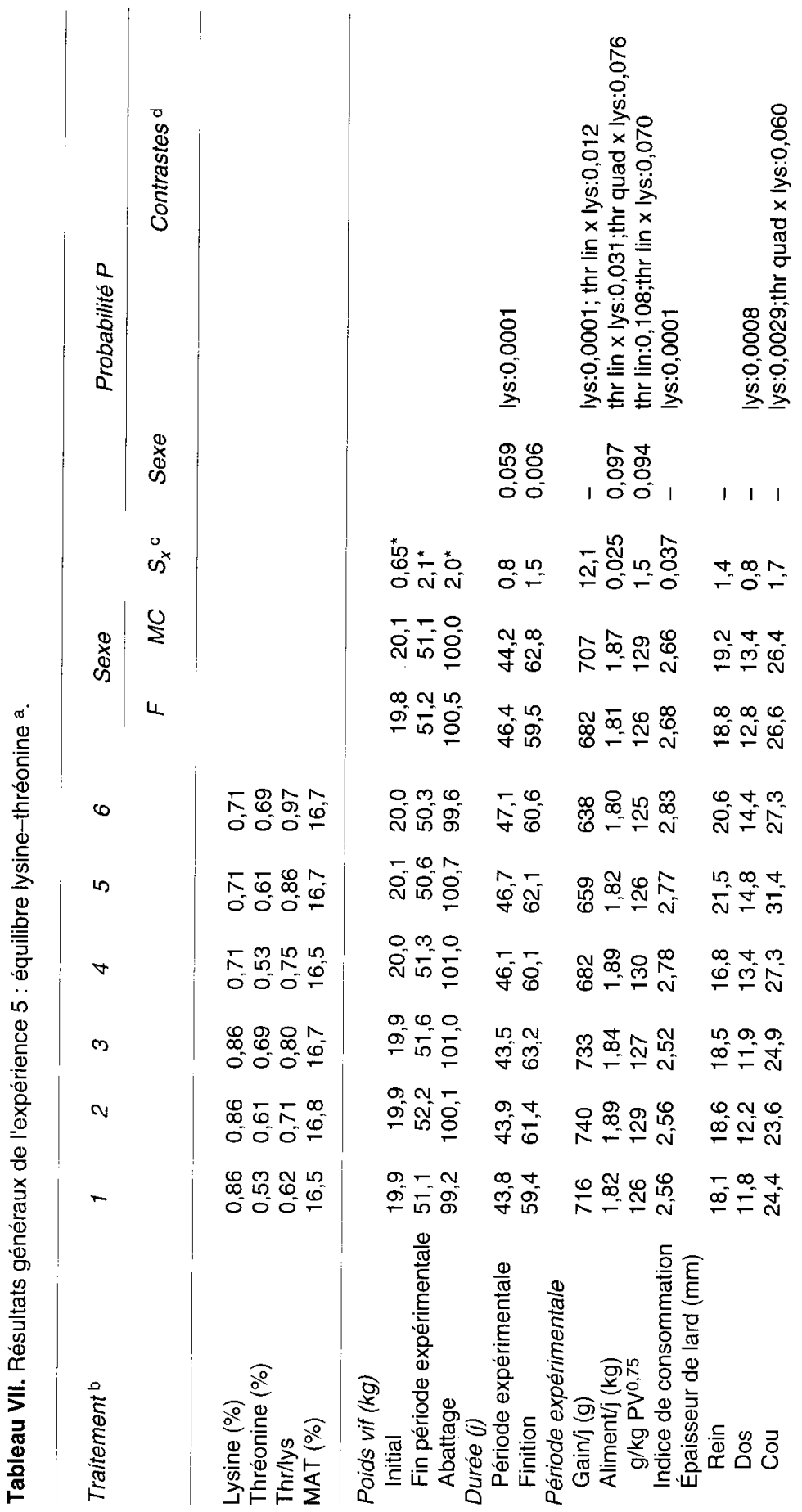




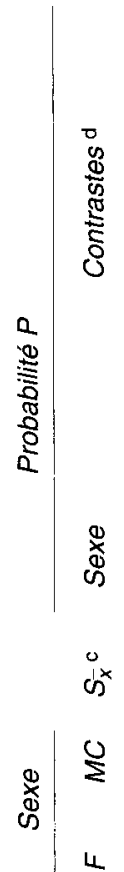

(o)

6

$\nabla$

$m$

N

$\frac{0}{\frac{1}{0}}$

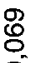

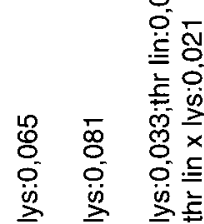

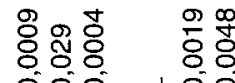

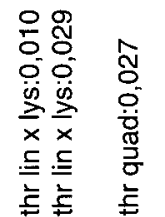

:

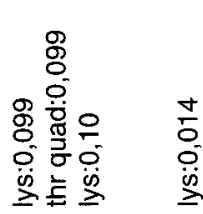

5

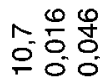

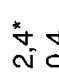

年兴

$0: 8$

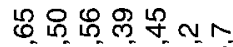

吉罾

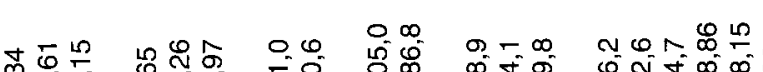

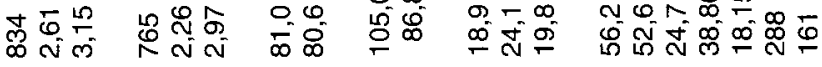

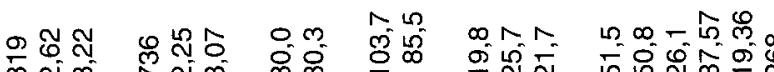

कू⿻ 万ल

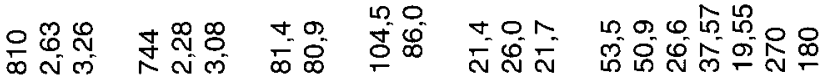

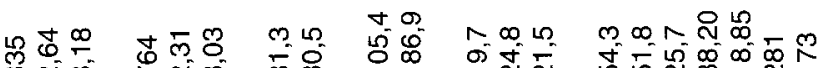

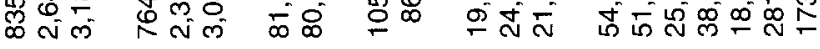

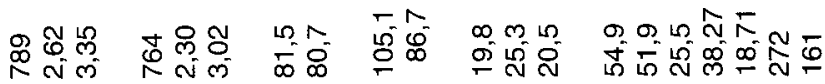

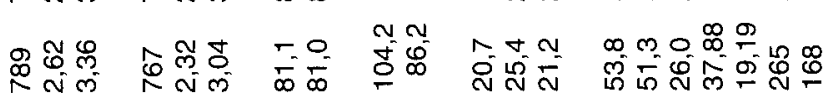

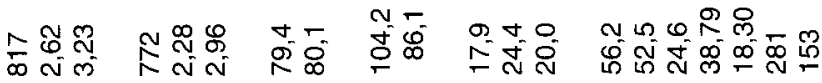

들

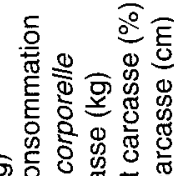

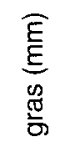

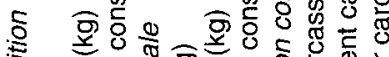

(⿻)

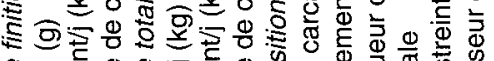


au bas taux de lysine, principalement chez les mâles castrés. La réduction du taux de lysine pendant la phase initiale de croissance (20-50 kg de poids vif) entraîne à l'abattage à $100 \mathrm{~kg}$ une augmentation de l'épaisseur de lard X4 $(P<0,10)$, associée à un accroissement du pourcentage de gras $(26,1$ vs 25,3$)$ et du dépôt journalier de gras (176 vs $51,9 \%$ ) et du poids de muscle $(-2,4 \%)$ après covariance sur le poids de la carcasse chaude $(P<0,10)$. L'apport accru de thréonine pendant la phase de croissance exerce un effet quadratique sur l'épaisseur de gras $\mathrm{X} 1(P<0,05)$, de même que sur le pourcentage et le poids final de gras $(P<$ 0,10 ), avec une adiposité plus élevée pour un rapport thréonine/lysine intermédiaire.

\section{DISCUSSION}

L'influence de l'alimentation pendant le jeune âge sur les performances ultérieures chez le porc doit être définie en fonction du stade de la vie de l'animal à laquelle elle s'applique, ainsi que des conditions d'alimentation au cours de l'engraissement. Dans le cas considéré, il s'agissait d'une alimentation à volonté dans un intervalle de poids se situant entre $18-20$ et $40-50 \mathrm{~kg}$, suivie en finition d'un même plan de rationnement alimentaire avec un aliment unique. Ce dernier, renfermant $17 \%$ de MAT et normalement utilisé pour l'ensemble des phases de croissance et de finition, visait à couvrir largement les besoins en acides aminés en fin d'engraissement. En effet, comme l'ont montré Sève et Ballèvre (1981), Kyriazakis et al (1991), Miller et al (1994), il convenait ainsi d'assurer la pleine expression du potentiel de croissance compensatrice, si celle-ci devait se manifester. De plus, les animaux étant soumis à un plan de rationnement, leurs besoins en acides aminés relativement à l'énergie s'en trouvaient accrus, comparativement à l'alimentation à volonté (Bourdon et Henry, 1991).
Les résultats des 5 essais mettent bien en évidence que les effets d'une déficience ou d'un déséquilibre du régime en acides aminés durant un stade défini de la croissance sur les performances en finition s'expliquent pour une bonne part par leur incidence particulière sur l'ingestion alimentaire, selon la nature des acides aminés impliqués, lorsque les animaux sont alimentés à volonté.

\section{Incidence du type de déficit ou déséquilibre en acides aminés sur l'ingestion alimentaire et la croissance}

Comme nous l'avons rapporté antérieurement (Henry, 1983, 1985), le porc réagit à un apport sub-optimal de lysine ou de thréonine en augmentant sa consommation par unité de poids métabolique, probablement en tentant de mieux couvrir son besoin pour l'acide aminé limitant, ce qui est en accord avec les observations de Boorman (1979) sur la régulation de l'appétit pour les acides aminés chez les volailles. II s'ensuit une croissance réduite par l'apport de l'acide aminé limitant, accompagnée d'une augmentation de l'adiposité, en raison du maintien, voire d'un accroissement, du niveau d'alimentation au dessus de l'entretien. Dans le cas du tryptophane, la situation est différente. Une réduction modérée de son apport en dessous du taux optimal pour la croissance (expérience 1) ne produit pas la réponse compensatrice observée avec la lysine et la thréonine. Au contraire, une déficience plus sévère provoque un effet fortement dépressif sur l'appétit et la croissance (expérience 2), ce qui confirme nos observations antérieures (Henry et Pastuszewska, 1976 ; Henry et al, 1986 ; Henry et al, 1992) et nos conclusions sur le rôle spécifique du tryptophane dans la synthèse de sérotonine, qui intervient à son tour dans la régulation centrale de l'ingestion alimentaire (Henry et al, 1992). Les dépôts journaliers 
de tissus maigres et de gras sont alors simultanément affectés par la déficience en tryptophane. Avec le gaspillage important d'aliment chez les porcs recevant des apports insuffisants de tryptophane, dans l'expérience 2 , on retrouve le phénomène d'aversion pour les régimes déséquilibrés en acides aminés chez les animaux soumis au libre choix, qu'il s'agisse du rat (Leung et al, 1968) ou du porc (Edmonds et al, 1987). Par ailleurs, en accord avec les observations initiales de Harper (1964), Peng et al (1973), un apport excessif de thréonine en présence d'une apport insuffisant de lysine (expériences 4 et 5) fournit un exemple de déséquilibre en acides aminés qui retentit défavorablement sur l'ingestion alimentaire : les porcs ont une croissance diminuée et déposent moins de gras. Au contraire, au taux optimal de lysine, l'amélioration de l'équilibre thréonine/lysine procure un effet bénéfique sur l'appétit des animaux, qui ont une croissance améliorée et déposent plus de gras. Ce résultat, à la suite d'observations antérieures (Henry et Sève, 1993 ; Sève, 1994), confirme que la prise alimentaire chez le porc en croissance peut être affectée par de faibles variations de la teneur en thréonine autour de l'optimum pour la croissance, dans le sens soit d'une augmentation (apport sub-optimal), soit d'une diminution (apport légèrement excédentaire). La spécificité de la thréonine du point de vue de son effet sur l'appétit pourrait être attribuée à l'inadaptation de son système d'oxydation, conduisant à son accumulation dans le compartiment sanguin dans le cas d'un léger excès alimentaire (Sève et Ballèvre, 1991; Sève, 1994).

En résumé, dans l'influence d'une simple déficience en un acide aminé limitant sur l'ingestion alimentaire chez le porc, il convient de distinguer d'une part la lysine et la thréonine, dont le déficit, s'il est léger, s'accompagne d'une hyperphagie compensatrice, et d'autre part le tryptophane, dont le déficit aboutit rapidement à une dépression de l'appétit. Secondairement, lorsqu'il s'agit de la lysine, la tendance à I'hyperphagie compensatrice peut être contrecarrée par un excès d'un autre acide aminé, en l'occurrence la thréonine, jusqu'à provoquer à son tour un effet dépressif sur la consommation d'aliment. Dans ces différents cas, les performances de croissance sont plus ou moins affectées selon le degré de couverture du besoin en l'acide aminé limitant qui est permis par le niveau d'ingestion alimentaire. II s'ensuit que la complexité des relations entre l'excès global de protéines et l'acide aminé limitant du régime, du point de vue de leur incidence sur l'appétit et la croissance, résulte de la nature particulière des acides aminés impliqués, par défaut ou par excès, dans le déséquilibre.

\section{Conséquences à long terme sur la composition corporelle et la conformation des carcasses}

Les conséquences d'une déficience ou d'un déséquilibre en acides aminés sur les performances en finition et la composition corporelle finale se dégagent tout naturellement des effets observés initialement sur l'ingestion alimentaire et la croissance. Un apport sub-optimal de lysine ou de thréonine affecte le dépôt de tissus maigres, mais l'accroissement du dépôt de gras qu'il procure est maintenu à l'abattage lorsqu'on applique un même plan d'alimentation pendant la finition. La légère amélioration de la croissance et de l'efficacité alimentaire en finition à la suite d'une déficience en lysine entre 20 et $50 \mathrm{~kg}$ de poids vif (expérience 5), comme après un apport sub-optimal de thréonine (expérience 3), conforte les résultats de la bibliographie concluant à l'effet bénéfique d'une restriction initiale en protéines (Hoberg et Zimmerman, 1978 ; Wahlstrom et Libal, 1983) ou en lysine (Thaler et al, 1986) sur les performances ultérieures 
en finition, en alimentation à volonté, ou dans le cas d'une alimentation restreinte suivant une restriction azotée (Campbell et Biden, 1978). Mais, dans l'ensemble, l'incidence sur les performances en finition reste faible. De même, Chiba $(1991,1992,1994)$ n'observait que peu d'effet d'un régime déficient en lysine entre 20 et $50 \mathrm{~kg}$ de poids vif sur les performances globales à $100 \mathrm{~kg}$.

À la différence de ce que l'on observe avec la lysine ou la thréonine, une déficience initiale en tryptophane, en réduisant le niveau d'ingestion d'aliment, affecte à la fois la croissance des tissus maigres et le dépôt de gras, à l'image d'un auto-rationnement alimentaire. Lorsque les animaux sont soumis de nouveau à une alimentation équilibrée, ils retrouvent leur potentiel de dépôt de tissus maigres et produisent des carcasses dont l'état d'adiposité est encore réduit au stade commercial d'abattage. Mais, il n'y a pas pour autant de croissance compensatrice, de sorte que le handicap de croissance après une carence initiale en tryptophane se retrouve au stade final de l'abattage. Ces observations ont été confirmées dans un essai complémentaire (Henry, non publié) où la teneur en tryptophane était abaissée de 0,15 à 0,12 pendant 42 j entre 19 et $39 \mathrm{~kg}$ de poids vif en moyenne, préalablement à une alimentation égalisée en finition. La diminution du niveau d'ingestion d'aliment de 1,35 à $1,17 \mathrm{~kg} / \mathrm{j}$ pendant la période expérimentale était accompagnée d'une réduction de la vitesse de croissance de 531 à $425 \mathrm{~g} / \mathrm{j}$ et de l'épaisseur du lard dorsal de 15,3 à 14,1 $\mathrm{mm}$. En finition, les performances étaient inchangées (respectivement 808 et $805 \mathrm{~g}$ pour le gain moyen journalier), tandis qu'à l'abattage les teneurs en muscle et en gras des carcasses étaient comparables $(50,6 \%$ pour le taux de muscle, respectivement 26,6 et $26,5 \%$ pour la teneur en gras).

Le même effet dépressif sur l'ingestion alimentaire, accompagné d'une diminution à la fois des dépôts de tissus maigres et de gras, est observé en présence d'un excès de thréonine dans un régime insuffisamment pourvu en lysine. Dans ce cas, la réduction de l'état d'adiposité à la fin de la période expérimentale est retrouvée au poids final d'abattage, après que les animaux ont été soumis au même régime alimentaire en finition.

En dehors des effets globaux sur la composition corporelle, une déficience ou un déséquilibre en acides aminés du régime peut affecter différemment la conformation des carcasses, et notamment leur longueur, au poids commercial d'abattage. C'est ainsi qu'à la suite d'un apport restreint de lysine entre 18 et $47 \mathrm{~kg}$ de poids vif (expérience 1) la longueur de la carcasse est augmentée au poids final de $100 \mathrm{~kg}$ comparativement à un régime témoin normalement pourvu en lysine en début de croissance. Cet allongement de la carcasse à un même poids d'abattage correspond à un profil de croissance initialement ralenti avec une adiposité accrue, suivi d'une croissance normale en finition. Dans l'expérience 1, il semble de la même façon qu'une restriction modérée de l'apport de tryptophane, en ralentissant légèrement la croissance, conduise à une augmentation de la longueur des carcasses au poids d'abattage de $100 \mathrm{~kg}$. En revanche, dans l'essai complémentaire rapporté précédemment (Henry, non publié) comparant 0,15 et $0,12 \%$ de tryptophane entre 19 et $39 \mathrm{~kg}$ de poids vif en moyenne, la dépression initiale de la croissance suivie d'une alimentation égalisée en finition ne provoquait aucune modification de la longueur des carcasses au poids final de $100 \mathrm{~kg}$. La longueur totale était respectivement de 101,3 et $101,7 \mathrm{~cm}$ pour 0,15 et $0,12 \%$ de tryptophane initialement, contre 85,2 et $85,5 \mathrm{~cm}$ pour la longueur restreinte.

Ces résultats corroborent nos observations antérieures (Henry et al, 1971 ; Henry, 1993a), montrant qu'une amélioration quantitative (taux de protéines) et qualitative (équilibre en acides aminés) de l'apport azoté dès la phase initiale de la croissance 
chez des animaux alimentés à volonté jusqu'à l'abattage contribue à l'obtention de carcasses plus courtes pour un même poids vif final, en raison d'une stimulation du développement des régions corporelles les plus précoces (jambon, poitrine) par rapport au développement en longueur (longe), selon le concept de la croissance différentielle des tissus et des compartiments corporels (McMeekan, 1940a,b,c ; Pàlsson et Vergès, 1952a,b ; Davies, 1974a,b ; Robison, 1976 ; Fowler, 1980).

Dans le cas de la thréonine (expériences 4 et 5), l'explication semble moins évidente. En présence d'un taux optimum de lysine, un apport optimum de thréonine, en favorisant la croissance initiale, favorise aussi la longueur de la carcasse à l'abattage. Inversement, un déséquilibre par excès de thréonine relativement à un déficit de lysine, en réduisant l'ingestion alimentaire et la croissance pendant la phase initiale, provoque une diminution de la longueur de la carcasse au même poids d'abattage de $100 \mathrm{~kg}$. Cette différence pourrait être liée à la composition corporelle à l'issue de la période expérimentale, l'adiposité accrue semblant en faveur du développement en longueur pendant la phase de finition. En tout état de cause, comme l'ont souligné Wyllie et Owen (1978) et de Greef et al (1992), la composition corporelle finale, en l'occurrence la répartition de l'énergie fixée entre les protéines et les lipides, de même probablement que la conformation des carcasses, peut être influencée par le passé nutritionnel et la composition corporelle antérieure. En d'autres termes, des séquences azotées variables au cours de la croissance peuvent agir d'une manière spécifique sur la conformation finale des carcasses, et de ce fait sur la répartition des pièces de découpe et leur valeur commerciale.

Les effets des variations d'équilibre entre la thréonine et la lysine sur l'ingestion alimentaire, les performances de croissance et la composition corporelle sont à distinguer suivant le niveau de l'apport de lysine relativement au besoin optimal pour la croissance. Au taux optimal de lysine, l'influence favorable de l'accroissement du rapport thréonine/lysine de 0,61 à 0,70 (expérience 4) sur l'appétit et la croissance confirme la valeur de ce rapport recommandée dans d'autres études (Wang et Fuller, 1990 ; Henry, 1993b ; Henry et Bourdon, 1993 ; Sève et al, 1993 ; Sève, 1994), soit aux alentours de 0,65 . À l'inverse, un déséquilibre entre la thréonine par excès et la lysine déficitaire retentit défavorablement sur l'appétit et la croissance. Les observations en finition ne font pas apparaître d'incidence sur les performances ultérieures lorsque les porcs sont soumis à une alimentation équilibrée.

Les résultats de ces différents essais font bien ressortir que le porc en finition conserve l'intégralité de son potentiel de développement musculaire à l'issue d'une phase de restriction de l'apport de l'acide aminé limitant dans un intervalle de poids compris entre $18-20 \mathrm{~kg}$ et $40-50 \mathrm{~kg}$. Ils indiquent aussi que l'ampleur du phénomène de croissance compensatrice succédant à une période de restriction azotée pendant le jeune âge semble limitée, même si elle dépend de la sévérité de la restriction (Wahlstrom et Libal, 1983) ou du génotype (Hogberg et Zimmerman, 1978 ; de Greef et al, 1992). En tout état de cause, I'influence d'une restriction azotée sur les performances ultérieures dépend du stade de la vie de l'animal auquel elle est appliquée, et peut conduire, si elle est suffisamment précoce, à des effets dépressifs à long terme sur la croissance musculaire (Sève et Ballèvre, 1991).

\section{CONCLUSION}

Les résultats de la présente étude ont montré qu'une restriction de l'apport de l'acide aminé limitant (lysine, thréonine ou trypto- 
phane) chez le porc, tout comme un déséquilibre en acides aminés (lysine - thréonine), dans un intervalle de poids compris entre $18-20$ et $40-50 \mathrm{~kg}$, peut induire des effets spécifiques sur les performances ultérieures en finition et sur la composition corporelle finale à $100 \mathrm{~kg}$, lorsque les animaux sont soumis à un même plan de rationnement alimentaire. Ces effets sont étroitement liés aux variations d'ingestion alimentaire consécutives aux manipulations de l'équilibre en acides aminés, selon la nature de ces derniers.

Deux types de réponse sont ainsi généralement observés, selon que le déficit ou le déséquilibre en acides aminés affecte distinctement ou simultanément les dépôts de tissus maigres et de gras. D'un côté, une restriction initiale affectant la croissance mais favorisant le dépôt de gras, du fait d'un appétit préservé (déficit en lysine ou en thréonine), entraîne un léger accroissement de l'adiposité des carcasses à l'abattage lorsque les conditions d'alimentation sont les mêmes pendant la phase de finition. De l'autre, une restriction initiale affectant à la fois la croissance musculaire et le dépôt de gras, par son effet dépressif sur l'appétit (déficit en tryptophane, apport excessif de thréonine en présence d'un déficit en lysine), peut produire à terme les mêmes effets qu'une restriction alimentaire globale, avec une réduction de l'adiposité des carcasses à l'abattage. Dans un cas comme dans l'autre, les effets sur le gain pondéral et l'efficacité alimentaire pendant la phase de finition sont faibles ou inexistants, ce qui permet de conclure à l'absence de croissance compensatrice après un déficit en acides aminés, tout au moins dans nos conditions d'alimentation égalisée, et malgré une légère tendance à une compensation à la suite d'une déficience initiale en thréonine dans l'expérience 3 ou en lysine dans l'expérience 4. Il en résulte que le handicap de croissance et d'efficacité alimentaire enregistré à la suite d'un déficit ou d'un déséquilibre en acides aminés au cours d'une phase initiale de la croissance est retrouvé à l'abattage, tandis que la composition corporelle finale, de même que la conformation des carcasses, peut s'en trouver modifiée.

On serait tenté de conclure qu'un ajustement progressif des apports d'acides aminés aux besoins des animaux tout au long de leur croissance contribue à la meilleure optimisation des performances finales. II n'en demeure pas moins que l'application de différentes séquences azotées pendant la croissance, si elles sont parfois sans incidence sur les performances globales de croissance et d'efficacité alimentaire, peut influencer la composition et la conformation des carcasses à l'abattage, et par voie de conséquence leur valeur commerciale. D'autres études sont nécessaires afin de bien maîtriser les variations des caractéristiques de composition et de conformation des carcasses à l'abattage, en fonction des niveaux des apports de nutriments énergétiques et d'acides aminés au cours des stades successifs de la croissance du porc. C'est tout le problème du rationnement alimentaire, énergétique et azoté, qui est ainsi posé.

\section{RÉFÉRENCES}

Boorman KN (1979) Regulation of protein and amino acid intake. In : Food Intake Regulation in Poultry (KN Boorman, BM Freeman, eds), British Poultry Science Ltd, Edinburgh, Royaume-Uni, 87-126

Bourdon D, Henry Y (1991) Réponse du porc en finition à la supplémentation du régime en lysine, en fonction du niveau de rationnement et selon le sexe. Joumées Rech Porcine en France 23, 111-118

Campbell RG, Biden RS (1978) The effect of protein nutrition between 5.5 and $20 \mathrm{~kg}$ live weight on the subsequent performance and carcass quality of pigs. Anim Prod 27, 223-228

Chiba LI (1991) Effects of dietary amino acids during 20 to $50 \mathrm{~kg}$ live body weight on subsequent performance and carcass characteristics of pigs. $J$ Anim $\mathrm{SCl}$ 69 (Suppt), 366

Chiba LI (1992) Effects of prior nutritional history on subsequent performance, carcass traits and organ weight of pigs. J Anim Sci 70 (Suppt), 372 
Chiba LI (1994) Effects of dietary amino-acid content between 20 and $50 \mathrm{~kg}$ and 50 and $100 \mathrm{~kg}$ live weight on the subsequent and overall performance of pigs. Livest Prod Sci 39, 213-221

Davies AS (1974a) A comparison of tissue development in Pietrain and Large White pigs from bith to $64 \mathrm{~kg}$ live weight. 1. Growth changes in carcass composition. Anim Prod 19, 367-376

Davies AS (1974b) A comparison of tissue development in Pietrain and Large White pigs from birth to $64 \mathrm{~kg}$ live weight. II. growth changes in muscle distribution. Anim Prod 19, 377-387

De Haer LCM, Luiting P, Aarts HLM (1993) Relations among individuals (residual) feed intake, growth performance and feed intake pattern of growing pigs in group housing. Livest Prod Sci 36, 233-253

Desmoulin B, Ecolan P, Bonneau M (1988) Estimation de la composition tissulaire des carcasses de porcs : récapitulatif de diverses méthodes utilisables en expérimentation. INRA Prod Anim 1, 59-64

Edmonds MS, Gonyou HW, Baker DH (1987) Effect of excess levels of methionine, tryptophan, arginine, lysine and threonine on growth and dietary choice in the pig. J Anim Sci 65, 179-185

Foster WH, Kilpatrik DJ, Heaney IH (1983) Genetic variation in the efficiency of energy utilization by the fattening pig. Anim Prod 37, 387-393

Fowler VR (1980) Growth in mammals for meat production. In : Growth in Animals (TJL Lawrence, ed), Butterworths, London, Royaume-Uni, 249-263

Greef KH de, Kemp B, Verstegen MWA (1992) Performance and body composition of fattening pigs of 2 strains during protein deficiency and subsequent realimentation. Livest Prod Sci 30, 141-153

Harper AE (1964) Amino-acid toxicities and imbalances. In : Mammalian Protein Metabolism (HN Munro, JB Allison, eds), Academic Press, New York, ĖtatsUnis, Vol II, 87-134

Henry $Y(1983)$ The effects of the dietary levels of lysine, threonine and tryptophan on the voluntary feed intake in the growing pig. In : 4 e Symposium international sur le métabolisme et la nutrition azotés (R Pion, $M$ Arnal, D Bonin, eds), Colloques de I'INRA, $n^{\circ} 16$, vol II, INRA, Paris, France, 407-410

Henry $Y$ (1985) Dietary factors involved in feed intake regulation in growing pigs: a review. Livest Prod Sci 12, 339-354

Henry $Y$ (1993a) Alimentation du porc pour la production de viande maigre : évolutions récentes et perspectives. INRA Prod Anim 6, 31-45

Henry $Y$ (1993b) Affinement du concept de la protéine idéale pour le porc en croissance. INRA Prod Anim 6, 199-212

Henry Y, Bourdon D (1993) Réduction des intrants azotés dans l'alimentation du porc en croissance : utilisation d'un modèle de régime à base de blé avec supplémentation en lysine, thréonine et méthionine. Journées Rech Forcine en France 25, 263-272

Henry Y, Pastuszewska B (1976) Conséquences d'une déficience du régime en tryptophane chez le porc sur le niveau d'ingestion et les performances de croissance. Ann Zootech 25, 143-148

Henry $Y$, Sève B (1991) Incidence de l'équilibre en acides aminés du régime sur l'appétit et la croissance du porc, selon le taux de protéines et leur nature : l'exemple du tryptophane. Journées Rech Porcine en France 23, 119-126

Henry $Y$, Sève B (1993) Feed intake and dietary amino acid balance in growing pigs with special reference to lysine, tryptophan and threonine. Pig News and Information 14 (1), 35N-43N

Henry $Y$, Rérat A, Tomassone R (1971) Étude du besoin en lysine du porc en croissance-finition. Application de l'analyse multidimensionnelle. Ann Zootech 20, 521-550

Henry Y, Duée PH, Rérat A, Pion R (1986) Determination of tryptophan requirement of growing pigs between 15 and $40 \mathrm{~kg}$ live weight. Nutr Rep Internat 34 , 565-573

Henry $Y$, Sève B, Colléaux $Y$, Ganier $P$, Saligaut $C$, Jégo $P(1992)$ Interactive effecs of dietary levels of tryptophan and protein on voluntary feed intake and growth performance in pigs, in relation to plasma amino acids and hypothalamic serotonin. J Anim Sci 70, 1873-1887

Hogberg MG, Zimmerman DR (1978) Compensatory responses to dietary protein, length of starter period and strain of pig. J Anim Sci 47, 893-899

INRA (1984) L'alimentation des animaux monogastriques : porc, lapin, volailles. INRA, Paris, France, $282 \mathrm{p}$

Leung PMB, Rogers QR, Harper AE (1968) Effect of amino-acid imbalance on dietary choice in the rat. J Nutr 95, 483-492

Karege C (1991) Influence de l'âge et du sexe sur l'utilisation de l'énergie et la composition corporelle chez le porc en croissance. Thèse université Montpellier II, Sciences et Techniques du Languedoc, $254 \mathrm{p}$

Kyriazakis I, Stamataris C, Emmans GC, Whittemore CT (1991) The effects of food protein content on the performance of pigs previously given foods with low or moderate protein contents. Anim Prod 52,165173

McMeekan CP (1940a) Growth and development in the pig, with special reference to carcass quality characters. I. General. J Agr Sci 30, 276-348

McMeekan CP (1940b) Growth and development in the pig, with special reference to carcass quality characters. II. The influence of the plane of nutrition on growth and development. J Agr Sci 30, 387-436

McMeekan CP (1940c) Growth and development in the pig, with special reference to carcass quality characters. III. The effect of the plane of nutrition on the 
form and composition of bacon pig. J Agr Sci 30 , $511-569$

Miller PS, Critser DJ, Lewis AJ, Wolverton CK (1994) The effects of dietary protein concentration on compensatory growth in barrows and gilts. In : Nebraska Swine Report (RK Johnson, ed), Institute of Agriculture and Natural Resources, University of Nebraska, Lincoln, NE, États-Unis, 17-19

Pàlsson $H$, Vergès JB (1952a) Effects of the plane of nutrition on growth and the development of carcass quality in lambs. I. The effects of high and low planes of nutrition at different ages. J Agr Sci 42, 1-92

Pàlsson $H$, Vergès JB (1952b) Effects of the plane of nutrition on growth and the development of carcass quality in lambs. II. Effects on lambs of $30 \mathrm{lb}$ carcass weight. J Agr Sci 42, 93-149

Peng Y, Gubin J, Harper AE, Vavich MG, Kemmerer AR (1973) Food intake regulation: amino-acid toxicity and changes in rat brain and plasma amino acids. J Nutr 103, 608-617

Robison OW (1976) Growth patterns in swine. J Anim Sci $42,1024-1035$

SAS (1990) SAS User's Guide: Statistics. SAS Inst Inc, Cary, NC, États-Unis

Sève B (1984) Effets à long terme de la réduction du taux de protéines dans une ration simplifiée de sevrage. Intérêts comparés de l'incorporation de poudre de lait et de la supplémentation en L-lysine $\mathrm{HCl}$. Journées rech porcine en France 16, 347-353

Sève B (1994) Alimentation du porc en croissance : intégration des concepts de protéine idéale, de disponibilité digestive des acides aminés et d'énergie nette. INRA Prod Anim 7, 275-291

Sève B, Ballèvre O (1991) Approches métaboliques du besoin en acides aminés chez le porc en croissance. Journées rech porcine en France 23, 91-110

Sève B, Ganier P, Henry Y (1993) Courbe de réponse des performances de croissance du porc à l'apport de thréonine digestible vraie mesurée au niveau iléal. Journées rech porcine en France 25, 255-261

Thaler RC, Libal GW, Wahlstrom RC (1986) Effect of lysine levels in pig starter diets on performance to $20 \mathrm{~kg}$ and on subsequent performance and carcass characteristics. J Anim Sci 63, 139-144

Wahistrom RC, Libal GW (1983) Compensatory responses of swine following protein insufficiency in grower diets. J Anim Sci 56, 118-124

Wang TC, Fuller MF (1990) The effect of the plane of nutrition on the optimum dietary amino acid pattern for growing pigs. Anim Prod 50, 155-164

Wyllie D, Owen JB (1978) Dietary protein content and the subsequent body composition and food intake of pigs. J Agric Sci 90, 69-76 